\title{
Merlin/ERM proteins regulate growth factor-induced macropinocytosis and receptor recycling by organizing the plasma membrane:cytoskeleton interface
}

\author{
Christine Chiasson-MacKenzie, ${ }^{1,2}$ Zachary S. Morris, ${ }^{1,2}$ Ching-Hui Liu, ${ }^{1}$ William B. Bradford, ${ }^{1}$ \\ Thijs Koorman, ${ }^{1}$ and Andrea I. McClatchey ${ }^{1,2}$ \\ ${ }^{1}$ Massachusetts General Hospital Cancer Center, Harvard Medical School, Charlestown, Massachusetts 02129, USA; ${ }^{2}$ Department \\ of Pathology, Massachusetts General Hospital, Harvard Medical School, Boston, Massachusetts 02115, USA
}

The architectural and biochemical features of the plasma membrane are governed by its intimate association with the underlying cortical cytoskeleton. The neurofibromatosis type 2 (NF2) tumor suppressor merlin and closely related membrane:cytoskeleton-linking protein ezrin organize the membrane:cytoskeleton interface, a critical cellular compartment that both regulates and is regulated by growth factor receptors. An example of this poorly understood interrelationship is macropinocytosis, an ancient process of nutrient uptake and membrane remodeling that can both be triggered by growth factors and manage receptor availability. We show that merlin deficiency primes the membrane:cytoskeleton interface for epidermal growth factor (EGF)-induced macropinocytosis via a mechanism involving increased cortical ezrin, altered actomyosin, and stabilized cholesterol-rich membranes. These changes profoundly alter EGF receptor (EGFR) trafficking in merlin-deficient cells, favoring increased membrane levels of its heterodimerization partner, ErbB2; clathrin-independent internalization; and recycling. Our work suggests that, unlike Ras transformed cells, merlin-deficient cells do not depend on macropinocytic protein scavenging and instead exploit macropinocytosis for receptor recycling. Finally, we provide evidence that the macropinocytic proficiency of NF2-deficient cells can be used for therapeutic uptake. This work provides new insight into fundamental mechanisms of macropinocytic uptake and processing and suggests new ways to interfere with or exploit macropinocytosis in NF2 mutant and other tumors.

[Keywords: Merlin/ERMs; membrane:cytoskeleton interface; macropinocytosis; EGFR/ErbB2; cholesterol-rich domains] Supplemental material is available for this article.

Received May 30, 2018; revised version accepted July 20, 2018.

The interface between the plasma membrane and the cortical cytoskeleton is dynamically maintained by proteins that link membrane lipids and/or proteins to the underlying actomyosin meshwork (Gauthier et al. 2012; Kusumi et al. 2012). By spatially organizing both, these linkages establish the architectural and biochemical features of the cell surface. One key function of this cellular compartment is to both modulate the activity of membrane receptors and respond to their activation. For example, membrane:cytoskeleton linkages can direct local interactions between receptors and their effectors and/or regulators; impact receptor dimerization, aggregation, and signal propagation; and control multiple aspects of endocytic trafficking (Jaqaman and Grinstein 2012; Kusumi et al. 2012). Conversely, receptor activation can trigger rapid local changes in membrane lipids and the associated

Corresponding author: mcclatch@helix.mgh.harvard.edu Article published online ahead of print. Article and publication date are online at http://www.genesdev.org/cgi/doi/10.1101/gad.317354.118. cortical cytoskeleton (Chiasson-MacKenzie and McClatchey 2018). Details of this dynamic functional interrelationship and how it influences cell behavior are poorly understood.

The epidermal growth factor receptor (EGFR) is a member of the ErbB family of receptor tyrosine kinases (RTKs) whose activities are tightly controlled in normal tissues and deregulated in many cancers (Lemmon et al. 2014). Ligand-activated EGFR homodimerizes or heterodimerizes with other ErbBs to activate key mitogenic and survival signals, including the phosphatidylinositol $3^{\prime}$ kinase (PI3K)-Akt and MEK-Erk pathways. EGFR/ErbB activation can also elicit membrane lipid and cortical cytoskeletal remodeling that drive essential changes in cell shape

(C) 2018 Chiasson-MacKenzie et al. This article is distributed exclusively by Cold Spring Harbor Laboratory Press for the first six months after the full-issue publication date (see http://genesdev.cshlp.org/site/misc/ terms.xhtml). After six months, it is available under a Creative Commons License (Attribution-NonCommercial 4.0 International), as described at http://creativecommons.org/licenses/by-nc/4.0/. 
and adhesion during morphogenetic processes (ChiassonMacKenzie and McClatchey 2018). Activated receptors are internalized via several mechanisms and either down-regulated via lysosomal trafficking or recycled back to the plasma membrane (Tomas et al. 2014). The endocytic trafficking of ErbBs is profoundly influenced by membrane lipids-particularly specific phospholipids, sphingolipids, and cholesterol—and the dynamic organization of the associated cortical cytoskeleton (Bertelsen and Stang 2014). Despite the immense effort dedicated to therapeutically blocking the mitogenic activity of ErbB receptors, particularly EGFR and ErbB2, remarkably little is known of how they elicit remodeling of the membrane:cytoskeleton interface, how that interface controls ErbB dimerization and endocytic fate, or how either of these biological activities impacts the behavior of normal and tumor cells.

Dramatic remodeling of the membrane:cytoskeleton interface is associated with membrane ruffling that enables macropinocytosis, an evolutionarily ancient mechanism by which cells obtain nutrients, sample their external environment, and control plasma membrane turnover (Buckley and King 2017). Successful macropinocytosis is associated with the exaggerated vertical extension of the actin-rich rims of membrane ruffles that flop over and fuse, entrapping fluid and extracellular nutrients that are then actively internalized in macropinocytic vesicles. In mammalian cells, macropinocytosis can be constitutive or triggered by growth factors such as EGF; however, growth factors do not always elicit ruffling, and ruffles do not always lead to successful macropinocytosis. Molecular studies and modeling indicate that the property of the membrane:cytoskeleton interface as an excitable medium is central to both, but it is not clear how this is tuned (Devreotes et al. 2017). It is also not clear how the processing of internalized macropinosomes is regulated. Much recent attention has focused on the importance of macropinocytosis as a mechanism by which Ras transformed tumor cells acquire and lysosomally process exogenous nutrients to meet their increased metabolic needs; however, macropinosomes are not always delivered to the lysosome (Buckley and King 2017). The recent appreciation that macropinocytosis is also an important conduit for the delivery of macromolecular cancer therapeutics to tumor cells further highlights the need to better understand this important cellular process (Ha et al. 2016).

We previously uncovered a critical role for the neurofibromatosis type 2 (NF2) tumor suppressor merlin in controlling the interrelationship between cortical actomyosin and EGFR (Curto et al. 2007; Chiasson-MacKenzie et al. 2015). Merlin is closely related to the membrane:cytoskeleton-linking ERM proteins (ezrin, radixin, and moesin) and has an important role in limiting their cortical distribution (Fehon et al. 2010; Hebert et al. 2012). Our studies showed that, in confluent cells, EGFR is immobilized on the cell surface via a mechanism that depends on an intact cortical actomyosin cytoskeleton and occurs rapidly in response to activation of EGFR itself; in the absence of merlin, increased cortical ezrin alters the configuration of cortical actomyosin and disables this mecha- nism (Chiasson-MacKenzie et al. 2015). Here we show that, instead, merlin deficiency renders the membrane:cytoskeleton interface markedly excitable in response to growth factors, "priming" cells for dramatic ruffling and macropinocytosis-features that are rescued by the restoration of $N f 2^{W T}$ expression or elimination of ezrin. Our data also suggest that $N f 2^{-/-}$liver and Schwann cells (SCs) do not depend on macropinocytic protein scavenging, unlike Ras-activated cells (Commisso et al. 2013). In contrast, we provide evidence that the actin-dependent stabilization of cholesterol/sphingolipid-rich membranes in the absence of merlin stabilizes the surface levels of the EGFR heterodimerization partner ErbB2 and favors macropinocytic recycling of EGFR. Importantly, we found that macropinocytic priming, accumulation of membrane cholesterol/sphingolipids and ErbB2, and altered EGFR trafficking are signatures of NF2 deficiency in multiple tumor-relevant cell types, suggesting novel biomarkers and therapeutic insight into these intractable tumors.

\section{Results}

\section{Merlin limits EGF-induced remodeling of cortical actomyosin}

Our previous studies revealed that merlin and ezrin influence the poorly understood interdependency between EGFR and the cortical cytoskeleton (Curto et al. 2007; Chiasson-MacKenzie et al. 2015). To better understand this relationship, we studied the cortical changes that occur in response to EGF stimulation in $\mathrm{Nf}^{-/-}$and $N f 2^{W T}$-expressing liver-derived epithelial cells (LDCs) (Chiasson-MacKenzie et al. 2015). We found that EGF elicited dramatic F-actin-rich circular dorsal ruffles (CDRs) within 10 min of stimulating $N f 2^{-/-}$cells but only modestly affected cortical actin in the presence of merlin despite activating equivalent levels of EGFR (Fig. 1A; Supplemental Fig. 1A). Both $N f 2^{-/-}$and $N f 2^{W T}$-expressing LDCs are nonmotile and grow in small colonies when subconfluent. In $N f 2^{-/-}$colonies, EGF-induced CDRs were prominent on interior cells and cells at the colony perimeter, which also exhibited marked peripheral ruffling. $\mathrm{Nf}^{-/-}$cells exhibited a constitutive accumulation of F-actin at the colony edge (Fig. 1A), and F-actin and myosin IIA accumulated in both dorsal and peripheral ruffles upon EGF stimulation (Fig. 1A; Supplemental Fig. 1B). Treatment with latrunculin A or jasplakinolide, which disrupt F-actin in different ways (Rotsch and Radmacher 2000), abolished dorsal and peripheral ruffling as well as the edge accumulation of cortical actomyosin (Supplemental Fig. 1C).

To understand why EGF elicited such different cortical cytoskeletal responses in the presence and absence of merlin, we focused on the earliest response to EGF stimulation. We found that within $2 \mathrm{~min}$, EGF triggered the formation of cortical actin patches or tiny rings that also contained ezrin and the Arp2/3 activator N-WASP and likely represent nascent CDRs in $\mathrm{Nf2}^{-/-}$cells but not $N f 2^{W T}$-expressing cells (Fig. 1B; Supplemental Fig. 1D). Notably, Texas red-labeled EGF ligand (TR-EGF), which marks activated EGF:EGFR complexes, often formed a 


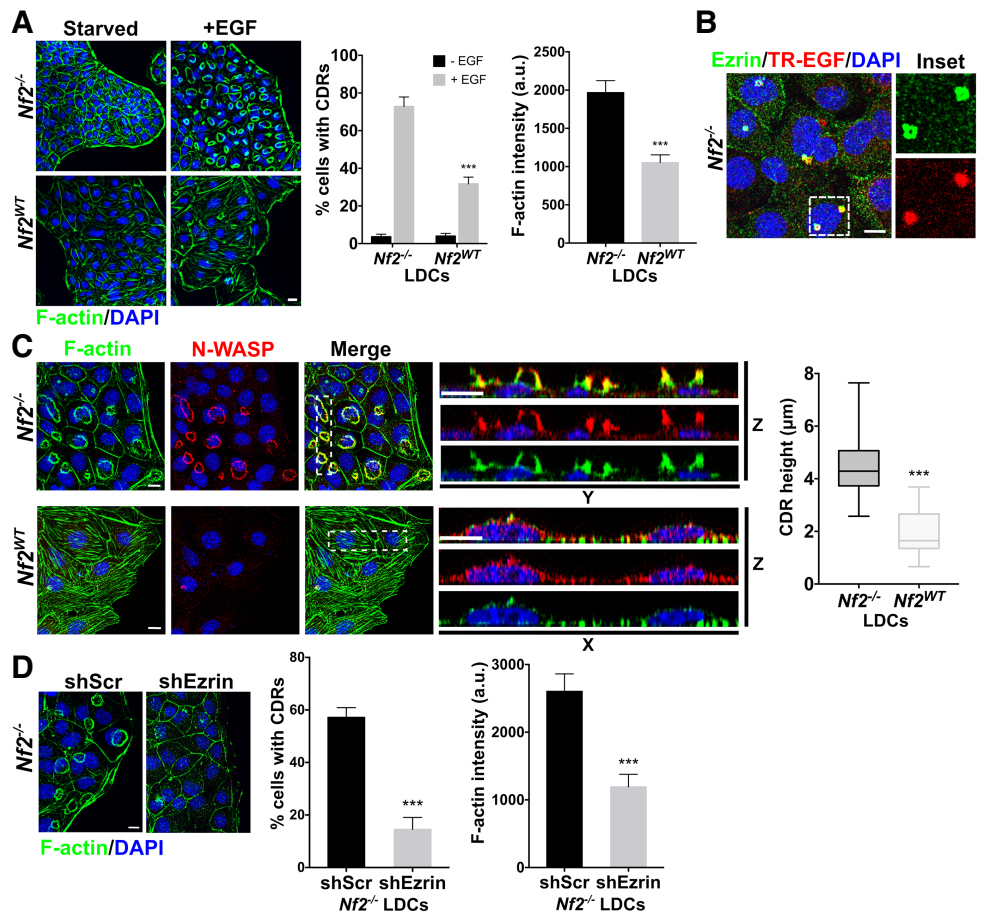

Figure 1. EGF-induced dorsal ruffling in the absence of merlin. $(A$, left $)$ Confocal images showing cortical F-actin before (starved) and after EGF stimulation for 10 min in $N f 2^{-l-}$ and $N f 2^{W T}$-expressing colonies. (Middle) The percentage of cells that formed at least one CDR after EGF stimulation. Note that many CDRs in Nf2 ${ }^{W T}$. expressing cells were small cortical "ripples." (Right) Quantitation of edge-accumulated F-actin in $\mathrm{Nf}^{-/}$ and $N f 2^{W T}$-expressing cells, measured as peak F-actin intensity using a line scan analysis (Smutny et al. 2010). (B) Cortical ezrin localization to tiny circular rings that encircle Texas red-labeled EGF ligand (TREGF) at 5 min after stimulation of $\mathrm{Nf2}^{-/-}$cells. (C) Distribution of F-actin and N-WASP across the cortex $(X-Y$ sections; left) and within the vertical extensions $(Y-Z$ and $X-Z$ sections; middle) of $N f 2^{-/-}$and $N f 2^{W T}$-expressing cells. (Right) The height of vertical extensions on the surface of $N f 2^{-/-}$and $N f 2^{W T}$-expressing cells. $(D, l e f t)$ Confocal images showing F-actin-rich CDRs in $\mathrm{Nf2}^{-/-}$ cells infected with shScr-expressing (control) or shEzrin-expressing lentiviruses (Hebert et al. 2012). (Middle) The percentage of shScr- or shEzrin-expressing $\mathrm{Nf}^{-/-}$ cells with CDRs. (Right) Quantitation of F-actin at the free edge of $\mathrm{Nf2}^{-/-}$and $\mathrm{Nf2}^{-l-}$; shEzrin-expressing cells.

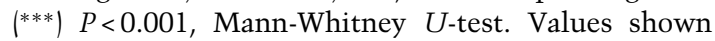
are mean \pm SEM. Bars, $A, 20 \mu \mathrm{m} ; B-D, 10 \mu \mathrm{m}$. "bull's-eye" at the center of these patches (Fig. 1B). While $\sim 75 \%$ of the $\mathrm{Nf2}^{-/-}$cells had one to two initiating patches or mature structures per cell, few $N f 2^{W T}$-expressing cells had any dorsal structure, and those that did form were much smaller (Fig. 1A-C). Most striking was the very different vertical architectures achieved by the structures that did form. The cortex of $N f 2^{W T}$-expressing cells remained largely flat, with only minor actin-containing surface "ripples" $(<1-4 \mu \mathrm{m})$ and little colocalization of Factin and N-WASP (Fig. 1C). In contrast, $\mathrm{Nf2}^{-/-}$cells formed large actin-enriched vertical membrane extensions $(3-8 \mu \mathrm{m})$ with a strong accumulation of N-WASP at the tips (Fig. 1C). Consistent with the ability of ectopic cortical ezrin to drive other phenotypes in $\mathrm{Nf}^{-/-}$cells, shRNA depletion of ezrin eliminated dorsal and peripheral ruffles as well as the edge accumulation of actomyosin in $\mathrm{Nf}^{-/-}$cells (Fig. 1D; Supplemental Fig. 1E; Hebert et al. 2012; Chiasson-MacKenzie et al. 2015). These data support the notion that merlin normally dampens EGF-induced cortical cytoskeletal remodeling and that in the absence of merlin, excess ezrin renders the cell cortex particularly "excitable."

\section{Merlin deficiency primes cells for macropinocytosis}

Both CDRs and peripheral ruffles can initiate the process of macropinocytosis when their vertical membrane extensions fold over and entrap extracellular fluid (Buckley and King 2017). Macropinocytosis has been particularly well studied in the amoeba Dictyostelium discoideum, where it has been shown to initiate from surface patches of Ras and PI3K-generated $\mathrm{PI}(3,4,5) \mathrm{P}_{3}$ that recruit a surrounding rim of Arp2/3-driven actin remodeling and vertical membrane extension to form a "macropinocytic cup" (Veltman et al. 2014, 2016). The structures that form on the surface of EGF-stimulated $\mathrm{Nf}^{-/-}$cells mirror that of classic macropinocytic cups (Fig. 1C).

To determine whether $\mathrm{Nf}^{-/-}$cells execute successful macropinocytic internalization, we monitored the uptake of the large dye dextran, an established marker of macropinocytosis. We found that fluorescently labeled dextran (dextran-488, 70,000 MW [molecular weight]) was internalized into large vesicular structures by $\mathrm{Nf2}^{-/-}$cells within 30 min of EGF stimulation; in contrast, few vesicles were marked by dextran-488 in EGF-stimulated $N f 2^{W T}$-expressing cells (Fig. 2A). Similarly, fluorescently labeled bovine serum albumin (BSA-488) was readily internalized by $N f 2^{-l-}$ but not $N f 2^{W T}$-expressing cells (Fig. 2B). Importantly, dextran-488 uptake by $\mathrm{Nf}^{-1-}$ cells was completely blocked by the macropinocytosis inhibitor 5 (N-ethyl-N-isopropyl) amiloride (EIPA), which blocks actin remodeling by inhibiting the $\mathrm{Na}^{+} / \mathrm{H}^{+}$exchanger and lowering submembranous $\mathrm{pH}$ (Fig. 2C; Koivusalo et al. 2010).

We next asked whether exaggerated cortical actomyosin dynamics and macropinocytosis are features of merlin deficiency in other tumor-relevant cell types. NF2 mutations underlie the development of schwannomas, meningiomas, and mesotheliomas in humans (Petrilli and Fernandez-Valle 2016). We found that EGF-induced ruffling and macropinocytosis were prominent in NF2-deficient human mesothelioma and mouse meningioma cells and significantly reduced upon re-expression of $\mathrm{Nf}^{W T}$ (Fig. 2D; Supplemental Fig. 2A). We then examined primary normal $\left(N f 2^{\text {lox/lox}}\right)$ and derivative $N f 2^{-l-}$ SCs from $N f 2^{l o x / l o x}$ mice (Giovannini et al. 2000). Primary SCs express negligible levels of EGFR and instead depend on Neuregulin ( $\mathrm{Nrg}$ )-activated ErbB2/3 heterodimers 


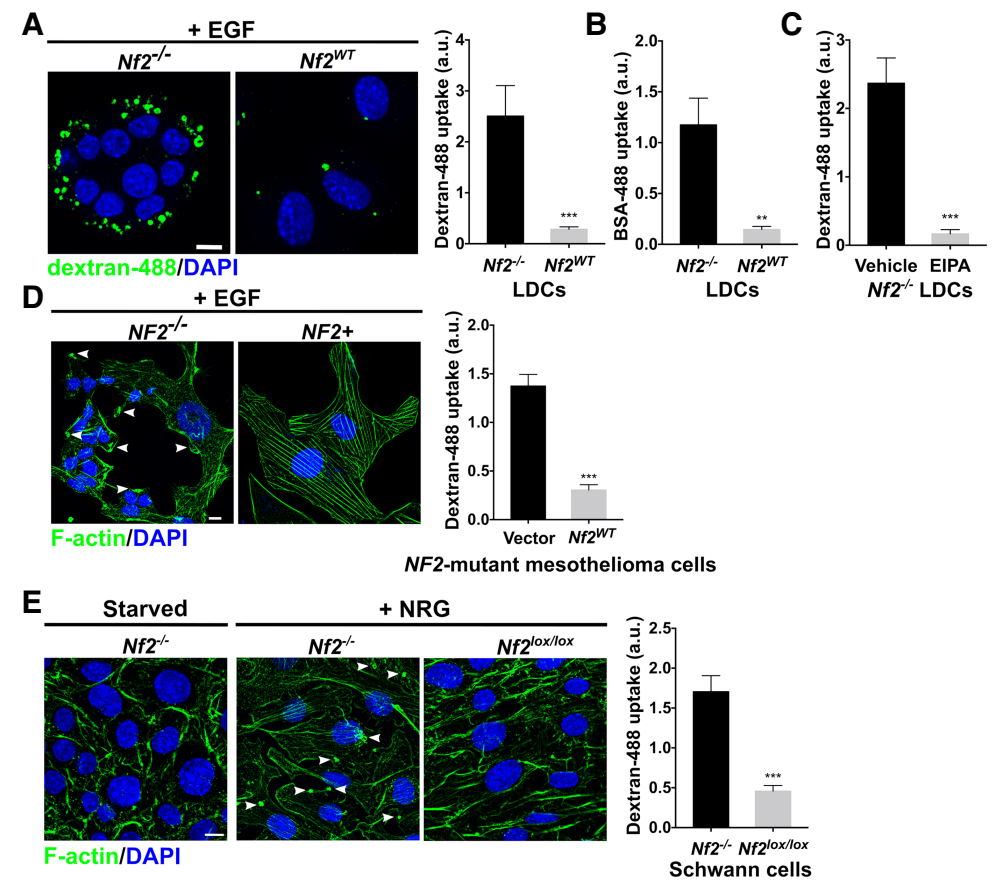

Figure 2. $N f 2^{-/-}$cells are primed for macropinocytosis. (A) Confocal images (left) and quantitation (right) of dextran- $488^{+}$macropinosomes in EGF-stimulated $N f 2^{-/-}$and $N f 2^{W T}$-expressing cells. (B) Quantitation of BSA- $488^{+}$macropinosomes after EGF stimulation. (C) Quantitation of dextran- $488^{+}$macropinosomes in EGF-stimulated $N f 2^{-/-}$cells treated with $50 \mu \mathrm{M}$ EIPA or vehicle (DMSO). (D, left) Confocal images of F-actin-labeled cortical ruffles (arrowheads) in EGF-stimulated $\mathrm{NF}^{-/-}$and $\mathrm{NF2}^{+}$mesothelioma cells. (Right) Quantitation of dextran- $488^{+}$macropinosomes in $N F 2^{-1-}$ and $N f 2^{W T}$-expressing mesothelioma cells. $(E$, left $)$ Confocal images of F-actin-labeled cortical ruffles (arrowheads) in starved and Nrg-stimulated primary $N f 2^{-/-}$and wild-type ( $\left.N f 2^{l o x / l o x}\right)$ SCs. (Right) Quantitation of dextran- $488^{+}$macropinosomes in $\mathrm{Nf}^{-/-}$and Nf2 ${ }^{10 x / l o x}$ SCs. $\left({ }^{* *}\right) P<0.01 ;\left({ }^{* * *}\right) P<0.001$, Mann-Whitney $U$-test. Values shown are mean \pm SEM. Bars, $10 \mu \mathrm{m}$.
(Salzer 2015). Stimulation with Nrg induced significant membrane ruffling and macropinocytosis in $\mathrm{Nf}^{-/-}$SCs but not in matched wild-type SCs (Fig. 2E). Thus, merlin deficiency broadly sensitizes cells to growth factor-induced cortical excitability and macropinocytosis.

\section{Altered macropinosome processing in $\mathrm{Nf2}$-deficient cells}

In addition to an increase in number, we noted that the dextran-488-positive macropinosomes in $\mathrm{Nf2}^{-/-}$cells were much larger than the few that formed in control cells (Fig. 3A). The small GTPase Rab5, the earliest marker of macropinosomes, marked vesicles of a similar size and distribution in EGF-stimulated $\mathrm{Nf2}^{-/-}$and $\mathrm{Nf2} 2^{W T}$-expressing cells (Supplemental Fig. 3A). In contrast, upon growth factor stimulation, the enlarged dextran-488-positive macropinosomes in $\mathrm{NF}^{-/-}$cells of all three cell types accumulated Rab7, which replaces Rab5 and is involved in trafficking macropinosomes to the lysosome (Fig. 3B; Supplemental Fig. 3B; Kerr and Teasdale 2009).

An enlarged Rab7 vesicle compartment is frequently associated with excessive cholesterol loading —as during foam cell formation by macrophages or in lysosomal storage disorders such as Niemann-Pick type $\mathrm{C}$-and can prevent transport to and fusion with the lysosome (Sobo et al. 2007; Huynh et al. 2008; Rai et al. 2016). Indeed, fluorescently labeled cholera toxin B (CTxB-488), which binds to the sphingolipid GM1 and marks cholesterol-rich membranes, localized prominently around the enlarged $\mathrm{Rab}^{+}$macropinosomes in $\mathrm{Nf2^{-/ }}$ cells following EGF stimulation (Fig. 3C; Maxfield and Wustner 2012). Moreover, treatment with methyl- $\beta$-cyclodextran $(\mathrm{M} \beta \mathrm{CD})$, which extracts membrane cholesterol, reduced Rab $7^{+}$vesicle size in $\mathrm{Nf2}^{-/-}$cells (Fig. 3C).
A role for ERM proteins in stabilizing cholesterol-rich domains in the plasma membrane has been proposed (Prag et al. 2007; Martinelli et al. 2013; Santos et al. 2013). We found that CTxB-488 was particularly enriched at the base of macropinocytic cups prior to their internalization; in fact, surface CTxB-488 levels were markedly elevated in $\mathrm{NF}^{-/-}$cells of all three types relative to controls (Fig. 3D,E; Supplemental Fig. 3C). These data suggest that internalized macropinosomes in $\mathrm{Nf2}^{-/-}$cells are formed from surface-derived cholesterol-enriched membrane. Similarly, the levels of membrane cholesterol itself (as measured by filipin labeling) and of flotillin (an independent marker of cholesterol-rich membranes) were elevated in $\mathrm{Nf}^{-/-}$cells (Supplemental Fig. 3D,E). Actomyosin cytoskeletal networks can control the spatial distribution and stability of cholesterol-rich membrane domains (Gowrishankar et al. 2012; Kusumi et al. 2012). Indeed, dextran $-488^{+}$and Rab7 $7^{+}$macropinosomes in $\mathrm{Nf2}{ }^{-/-}$cells were specifically encircled by actin, and shEzrin expression blocked macropinocytosis and reduced the size of $\mathrm{Rab}^{+}$vesicles in $\mathrm{Nf}^{-/-}$cells (Fig. 3F-H; Supplemental Fig. 3F). While it is clear that most macropinosomes undergo scission and completely internalize (Supplemental Fig. 3F), we cannot rule out the possibility that cholesterol loading causes some to stall, which could contribute to signal amplification. These data suggest that in the absence of merlin, ectopic ezrin and altered cortical actin stabilize cholesterol-rich membrane domains, influencing the uptake and processing of macropinosomes.

We compared macropinosomes formed by $\mathrm{Nf2}^{-1-} \mathrm{SCs}$ with those of SCs lacking the NF1 tumor suppressor, which encodes an established Ras inhibitory GTPase-activating protein (RasGAP) (Cichowski and Jacks 2001). Like Ras transformed mammalian cells, strains of 
A
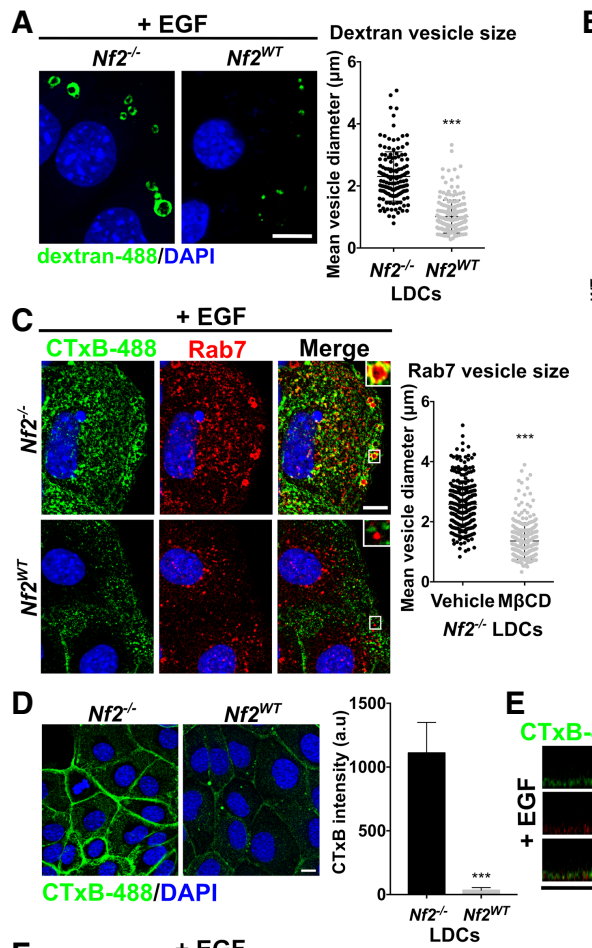

E

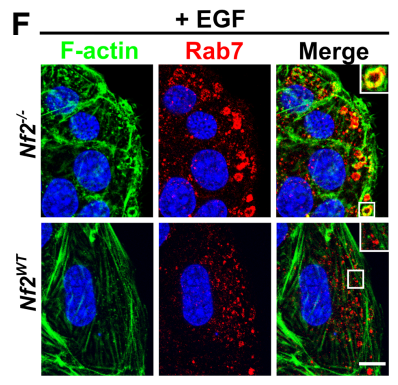

B

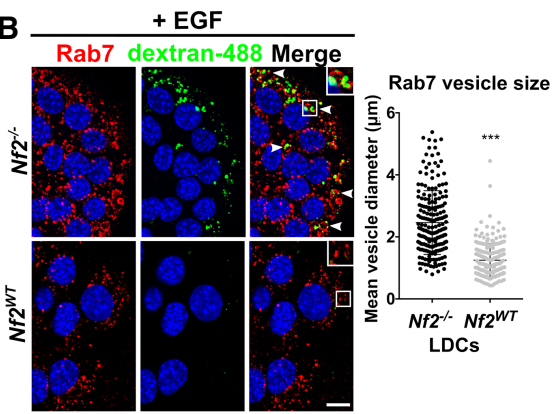

Figure 3. Increased membrane cholesterol and altered macropinosome processing in the absence of merlin. $(A$, left $)$ Highpower images of dextran- $488^{+}$macropinosomes in EGF-stimulated $\mathrm{Nf2^{-/- }}$ and $N f 2^{W T}$-expressing cells. (Right) The diameter of dextran- $488^{+}$vesicles in EGF-stimulated $\mathrm{Nf2^{-/ }}$ and $\mathrm{Nf} 2^{W T}$-expressing cells. $(B$, left $)$ Confocal images showing enlarged Rab7 ${ }^{+}$and dextran- $488^{+}$macropinosomes in EGF-stimulated $\mathrm{Nf2} 2^{-/}$and $\mathrm{Nf2}{ }^{W T}$-expressing cells. (Right) Rab7 ${ }^{+}$vesicle size in EGF-stimulated $\mathrm{Nf2} 2^{-/-}$and $\mathrm{Nf2}{ }^{W T}$-expressing cells. $(C$, left $)$ Confocal images showing the distribution of cholera toxin B (CTxB-488) and Rab7 to macropinocytic vesicles in $\mathrm{Nf2} 2^{-/-}$cells after incubation with CTxB-488 and EGF for $30 \mathrm{~min}$ at $37^{\circ} \mathrm{C}$. (Right) Quantitation of Rab7 ${ }^{+}$vesicle size in $\mathrm{Nf2^{-/ }}$ cells treated with vehicle (water) or $10 \mathrm{mM} \mathrm{M} \beta \mathrm{CD}$. (D) Confocal images (left) and quantitation (right) of surface-labeled CTxB-488 after $30 \mathrm{~min}$ at $4^{\circ} \mathrm{C}$ in unstimulated $N f 2^{-/-}$and $N f 2^{W T}$-expressing cells. (E) $X-Z$ confocal images showing CTxB-488 and N-WASP localization on the dorsal surface of EGF-stimulated $\mathrm{Nf}^{-/-}$cells. $(F)$ Confocal images showing the distribution of $\mathrm{F}$-actin relative to Rab7 in EGF-stimulated $N f 2^{-/-}$and $N f 2^{W T}$-expressing cells. (G) Quantitation of dextran-488 uptake in $\mathrm{Nf2} 2^{-/-}$cells infected with shScr- or shEzrin-expressing lentiviruses. $(H)$ Quantitation of Rab7 ${ }^{+}$ vesicle size in $\mathrm{Nf2}^{-/-}$cells infected with shScr- or shEzrin-expressing lentiviruses. Error bars indicate mean $\pm \mathrm{SD}$. $(A, B, C, H)$ or SEM. $\left(^{* * *}\right) \quad P<0.001$, Mann-Whitney $U$-test. Bars, $10 \mu \mathrm{m}$.

Dictyostelium carrying a mutation in the NF1 ortholog exhibit excessive macropinocytosis (Bloomfield et al. 2015). Familial NF1, like NF2, features the development of SC-derived tumors known as neurofibromas but has distinct features or anatomical distribution relative to NF2 mutant schwannomas (Lin and Gutmann 2013). We found that, in contrast to control or $\mathrm{Nf}^{-/-} \mathrm{SCs}, \mathrm{Nf1} 1^{-/-}$ SCs exhibit constitutive rather than growth factor-induced dextran-488 uptake (Fig. 4A; Supplementary Fig. 4). Furthermore, macropinosomes in $\mathrm{Nf1}^{-/-} \mathrm{SCs}$, like control SCs (Fig. 3B), were markedly smaller than those of Nrg-induced $\mathrm{Nf}^{-/-}$SCs and lacked Rab7 accumulation (Fig. 4B,C). Finally, in striking contrast to $\mathrm{Nf}^{-/-} \mathrm{SCs}$, $\mathrm{Nf1}^{-/-}$SCs exhibited little to no plasma membrane or vesicular CTxB-488 (Fig. 4D).

Ras transformed pancreatic tumor cells undergo constitutive macropinocytosis and exploit it to acquire amino acids via the lysosomal degradation of internalized extracellular protein. As such, cultured Ras transformed cells can survive and proliferate in the absence of free extracellular glutamine by breaking down exogenously provided BSA (Commisso et al. 2013). However, we found that $N f 2^{-/-}$LDCs and SCs were not able to exploit exoge- nous BSA to survive under conditions of glutamine deprivation (Fig. 4E). Moreover, $N f 2^{-/-}$cells were relatively insensitive to the lysosomal acidification inhibitor hydroxychloroquine (HCQ) or inhibition of PIKfyve localization (FTY720), which is important for the lysosomal processing of both autophagosomes and macropinosomes (Fig. 4F; Kim et al. 2016). Together, these data suggest that, unlike Ras transformed pancreatic cells, Nf2-lLDCs and SCs do not depend on or receive benefit from the lysosomal processing of exogenous protein. These results are consistent with a model in which stabilization of actin-associated cholesterol-rich membranes in the absence of merlin alters the processing of growth factor-induced macropinosomes.

\section{Increased EGFR recycling in the absence of merlin}

Cells undergoing significant macropinocytosis internalize a considerable portion of their membrane and must have an efficient mechanism for recycling membrane and receptors back to the surface (Buckley and King 2017). In fact, neurons depend on macropinocytic recycling to maintain sufficient surface receptors during high synaptic 


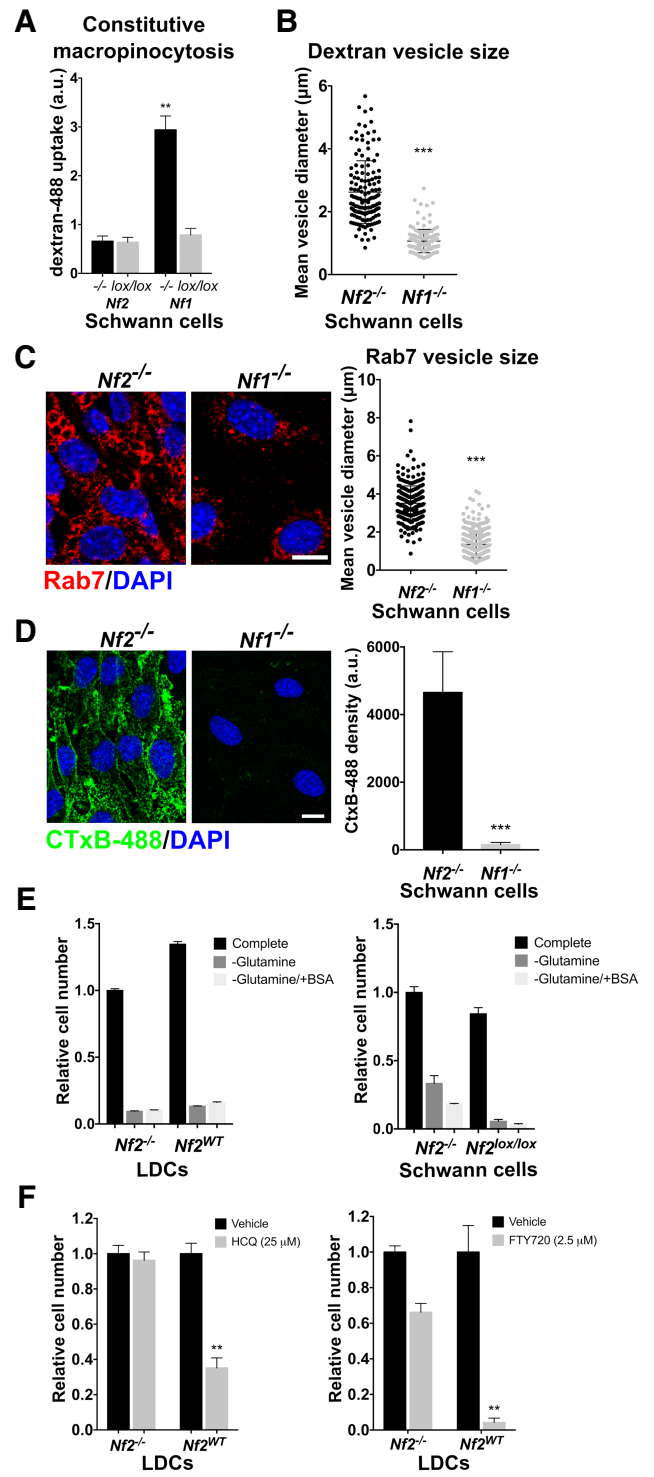

Figure 4. Altered macropinosome processing in $\mathrm{Nf2}^{-/-}$cells. (A) Levels of constitutive dextran-488 uptake in $\mathrm{Nf2}{ }^{--}, \mathrm{Nf1}-$ and control $\left(N f 2^{\text {lox/lox }}\right.$ or $\left.N f 1^{\text {lox/lox}}\right)$ primary SCs. $(B)$ Dextran$488^{+}$vesicle size in primary $\mathrm{Nf2} 2^{-/-}$and $\mathrm{Nf1}^{-/-}$SCs. (C) Confocal images (left) and quantitation (right) of $\mathrm{Rab}^{+}$vesicle size in Nrgstimulated $\mathrm{Nf2}^{-/-}$and $\mathrm{Nf1}^{-/-}$SCs. $(D)$ Distribution (left) and quantitation (right) of CTxB levels following 10 min of Nrg stimulation of live $\mathrm{Nf2^{-/- }}$ and $\mathrm{Nf1^{-/- }}$ SCs. (E) Relative viability of $N f 2^{-/-}$and $N f 2^{W T}$-expressing LDCs (left) and SCs (right) cultured in the absence of glutamine with or without exogenously added $2 \%$ BSA. $(F)$ Relative viability of $N f 2^{-/-}$and $N f 2^{W T}$-expressing LDCs cultured in complete medium in the presence of vehicle (DMSO), $25 \mu \mathrm{M}$ hydroxychloroquine (HCQ; left), or $2.5 \mu \mathrm{M}$ FTY720 (right). Values represent mean values \pm SD $(B, C)$ or SEM $(A, D-F) .\left(^{* *}\right) P<0.01 ;\left(^{* * *}\right) P<0.001$, Mann-Whitney $U$-test for $A-E$ or Student's $t$-test for $F$. Bars, $10 \mu \mathrm{m}$.

activity (Clayton and Cousin 2009). It has been shown that macropinocytic structures can actively concentrate and internalize a significant fraction of surface EGFR and other receptors (Orth et al. 2006; Schmees et al. 2012). The mechanisms controlling whether macropinosomes and their associated receptors are recycled or lysosomally processed are not understood, but exploitation of this balance to favor recycling of EGFR or other mitogenic receptors could provide an advantage to $\mathrm{Nf}^{-/-}$cells (Tomas et al. 2014; Francavilla et al. 2016). We observed that EGFR trafficking proceeded in strikingly different ways in $N f 2^{-/-}$and $N f 2^{W T}$-expressing cells. In addition to concentrating in nascent dorsal ruffles/macropinocytic cups (Fig. 1B), TR-EGF and EGFR accumulated at the free edge of $\mathrm{Nf2}^{-1-}$ cells (a site of vigorous peripheral ruffling and macropinocytosis) within $2 \mathrm{~min}$ of stimulation but localized to individual dispersed puncta by $30 \mathrm{~min}$ (Fig. 5A; Supplemental Fig. 5A). In contrast, in $N f 2^{W T}$-expressing cells, TR-EGF labeled tiny dispersed puncta that increased in size by $30 \mathrm{~min}$ (Fig. 5A). Acid wash removed little of the accumulated TR-EGF at $2 \mathrm{~min}$ in $\mathrm{Nf2}^{-/-}$cells, indicating that TR-EGF:EGFR complexes rapidly accumulate in a submembranous endocytic compartment (Supplemental Fig. 5B). This pattern of rapid TR-EGF accumulation in $\mathrm{Nf2} 2^{-/-}$cells was independent of the concentration of EGF used and provided a readily quantitative assay for investigating mechanisms of EGFR trafficking in $\mathrm{Nf}^{-/-}$ cells (Supplemental Fig. 5C).

Disruption of actin or elimination of ezrin abolished the early submembranous accumulation of TR-EGF:EGFR in $\mathrm{Nf2} 2^{-/-}$cells without blocking internalization (Fig. 5B; Supplemental Fig. 5D). We observed previously that activated EGFR biochemically fractionates with cholesterolrich membranes and exhibits a cholesterol-sensitive change in mobility in the absence of merlin (Curto et al. 2007; Chiasson-MacKenzie et al. 2015). Indeed, treatment of $N f 2^{-/-}$cells with $\mathrm{M} \beta \mathrm{CD}$ or simvastatin, which inhibits cholesterol production, also eliminated the unique pattern of TR-EGF internalization in $\mathrm{Nf2}^{-/-}$cells (Fig. 5C; Supplemental Fig. 5E). In contrast, the internalized transferrin receptor, which undergoes clathrin-mediated endocytosis (CME), did not accumulate submembranously in $N f 2^{-/-}$cells and was unaffected by M $\beta C D$ (Supplemental Fig. 5F). This is consistent with the exclusion of clathrinlabeled vesicles from this region of $\mathrm{Nf2}^{-/-}$cells (Supplemental Fig. 5G). Conversely, in $N f 2^{W T}$-expressing cells, TR-EGF internalization was unaffected by $\mathrm{M} \beta \mathrm{CD}$ but was blocked by the CME inhibitor chlorpromazine (CPZ), which did not affect TR-EGF in $\mathrm{Nf2}^{-/-}$cells (Supplemental Fig. 5H,I). As expected, CPZ blocked the internalization of the CME cargo transferrin in $N f 2^{W T}$. expressing cells (Supplemental Fig. 5I). Together, these data suggest that in the absence of merlin, changes in the membrane:cytoskeleton interface direct clathrin-independent trafficking of EGFR.

Macropinocytosis is clathrin-independent and has been linked to high membrane cholesterol (Grimmer et al. 2002; Mercer and Helenius 2009). Indeed, EIPA markedly reduced internalized TR-EGF in $N f 2^{-/-}$cells, supporting the idea that a substantial fraction of EGFR internalizes via macropinocytosis (Fig. 5D). To determine whether the fate of internalized EGFR is altered in the absence of merlin, we monitored EGFR turnover after EGF stimulation in the presence of cyclohexamide. While EGF 

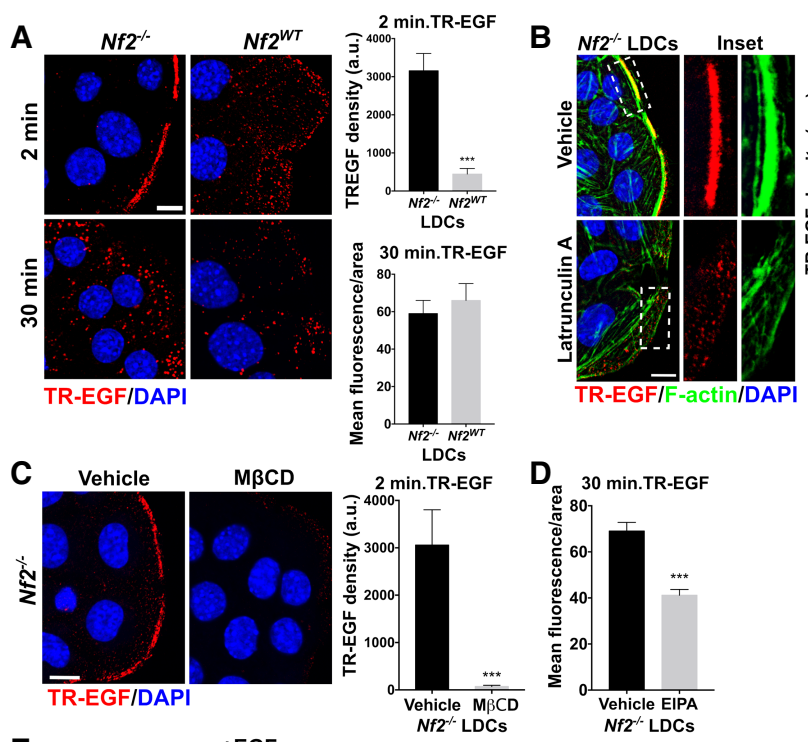

E
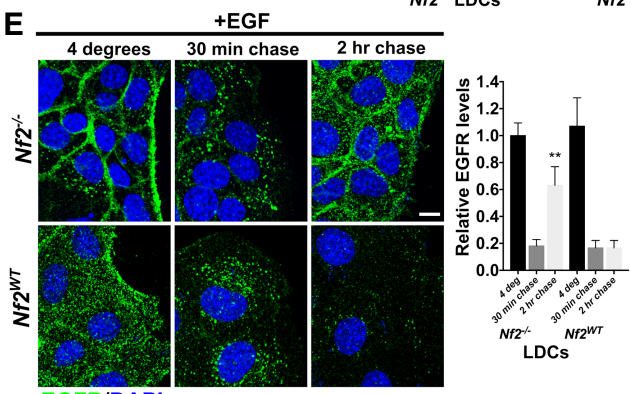
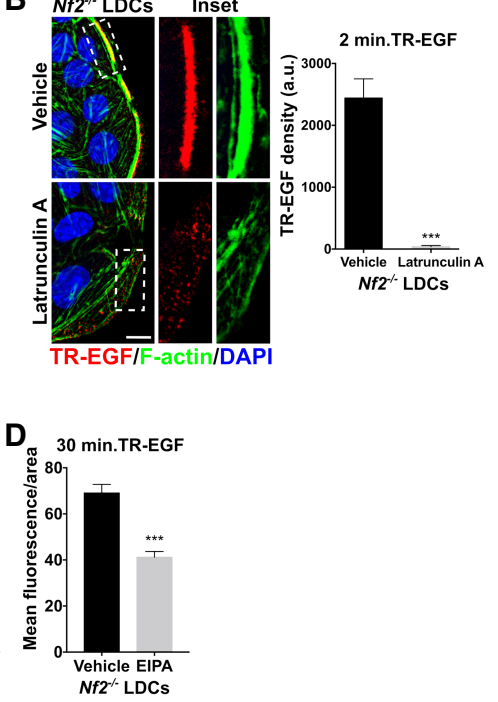

EGFR/DAPI

stimulation led to a rapid loss of surface EGFR in both $\mathrm{Nf2} 2^{-/}$and $\mathrm{Nf2}{ }^{W T}$-expressing cells, EGFR quickly reappeared at the plasma membrane in $\mathrm{Nf2}^{-/-}$cells but not $N f 2^{W T}$-expressing cells (Fig. 5E). Similarly, immunoblotting revealed a marked down-regulation of total EGFR in $\mathrm{Nf2}{ }^{W T}$-expressing cells but not $\mathrm{Nf2^{-/- }}$ cells, also consistent with the idea that EGFR is preferentially recycled in the absence of merlin (Supplemental Fig. 5J).

It is well established that ErbB2 localizes to membrane protrusions and ruffles and preferentially distributes to cholesterol/GM1-rich plasma membrane domains (Nagy et al. 2002; Hommelgaard et al. 2004; Bertelsen and Stang 2014). Moreover, ErbB2 is resistant to down-regulation and can confer that resistance-along with clathrin-independent internalization - to EGFR; instead, ErbB2:EGFR heterodimers preferentially recycle relative to EGFR homodimers (Nagy et al. 2002; Hendriks et al. 2003; Haslekas et al. 2005). We found that merlin-deficient cells exhibited elevated surface levels of ErbB2 that are sensitive to $\mathrm{M} \beta \mathrm{CD}$ (Fig. 6A,B). In fact, ErbB2 colocalizes with both CTxB-488 and TR-EGF at 2 min after stimulation, and ErbB2 and TR-EGF colocalized in discrete vesicles in $\mathrm{Nf2^{-/- }}$ cells at $30 \mathrm{~min}$ after stimulation (Fig. 6B; Supplemental Fig. 6A). ErbB2 can also impose alterations upon EGFR signaling (Li et al. 2012); indeed, we found that EGF stimulation yielded a strikingly different pattern of pAkt but not pErk in $\mathrm{Nf2}^{-/-}$and $\mathrm{Nf2}{ }^{W T}$-expressing cells despite similar stimulated levels (Fig. 6C; Supplemental
Figure 5. Actin- and cholesterol-dependent EGFR recycling in $N f 2^{-/-}$cells. (A) Distribution (left) and quantitation (right) of TR-EGF in $\mathrm{Nf}^{-/-}$and $\mathrm{Nf2}{ }^{W T}$. expressing cells at 2 and $30 \mathrm{~min}$ after stimulation. Quantitation at $2 \mathrm{~min}$ was limited to a $5-\mu \mathrm{m}^{2}$ box at the cell edge to capture the spatial difference in TREGF (top), and, at $30 \mathrm{~min}$, internalized TR-EGF across the entire cell area was quantitated (bottom). (B) Confocal images (left) and quantitation (right) showing the pattern of internalized TR-EGF and F-actin in $\mathrm{Nf2^{-/- }}$ cells treated with $10 \mu \mathrm{M}$ latrunculin A. (C) Distribution (left) and quantitation (right) of TR-EGF 2 min after stimulation in $N f 2^{-/-}$or $N f 2^{W T}$-expressing cells treated with vehicle or $10 \mathrm{mM} \mathrm{M} \beta \mathrm{CD}$. (D) Quantitation of TR-EGF ${ }^{+}$vesicles following $30 \mathrm{~min}$ of stimulation in $\mathrm{Nf2}^{-/-}$cells treated with vehicle (DMSO) or 50 $\mu \mathrm{M}$ EIPA. (E) Confocal images (left) and quantitation (right) depicting total EGFR levels in $\mathrm{Nf2}^{-/-}$or $N f 2^{W T}$-expressing cells pretreated with cyclohexamide and stimulated with EGF for $30 \mathrm{~min}$ at $4^{\circ} \mathrm{C}$ (left) and then transferred for $30 \mathrm{~min}$ or $2 \mathrm{~h}$ to $37^{\circ} \mathrm{C}$. Error bars represent mean \pm SEM. $\left(^{* *}\right) P<0.01 ;\left({ }^{* * *}\right) P<$ 0.001, Mann-Whitney $U$-test. Bars, $10 \mu \mathrm{m}$.
Figs. 1A, 6C). In $\mathrm{Nf2}^{-/-}$cells, EGF stimulation yielded a strong accumulation of pAkt in ruffling areas of the cell-including specifically in CDRs-that was ezrin-, actomyosin-, and cholesterol-dependent (Fig. 6C,D; Supplemental Fig. 6B). In contrast, EGF stimulation yielded diffusely localized pErk in $\mathrm{Nf}^{-/-}$cells (Supplemental Fig. 6C). In $N f 2^{W T}$-expressing cells, EGF triggered diffuse localization of both pAkt and pErk (Fig. 6C; Supplemental Fig. 6C). The pan-PI3K inhibitor GDC0941 blocked ruffling and macropinocytosis in $\mathrm{Nf2}^{-/-}$cells but not the formation of actin-rich initiating patches (Supplemental Fig. 6D), consistent with the established requirement of PI3K-induced PI $(3,4,5) \mathrm{P} 3$ in mature macropinocytic cup formation (Maekawa et al. 2014; Veltman et al. 2016). Together, these data suggest a model in which the altered configuration of actomyosin- and cholesterol-rich membranes in the absence of merlin promotes EGFR:ErbB2 heterodimerization, locally amplified PI3K activity, cortical cytoskeletal excitation, macropinocytosis, and recycling of a substantial fraction of internalized EGFR. These signatures of NF2 deficiency were also evident in mesothelioma cells (Supplemental Fig. 6E).

\section{Translational implications of merlin-deficient macropinocytic priming}

Our studies have novel translational implications for NF2 mutant tumors. First, a prediction of our studies is that 


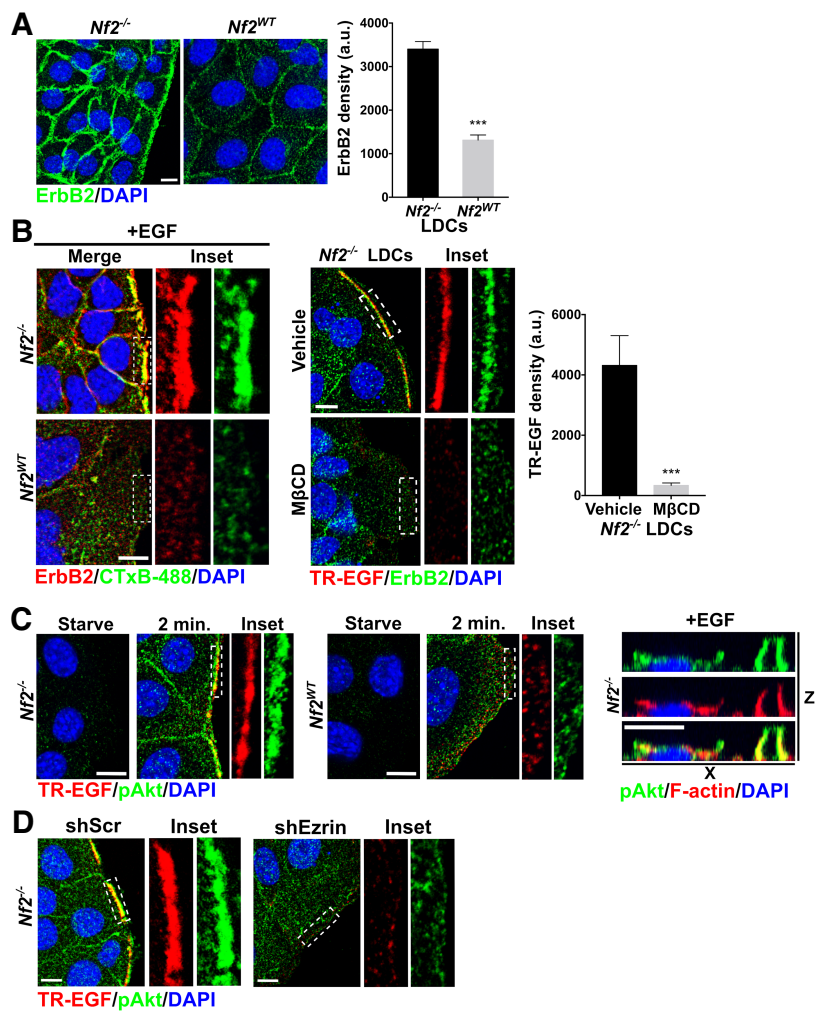

Figure 6. Merlin controls the surface levels of ErbB2 and spatial distribution of pAkt. (A) Confocal images (left) and quantitation (right) of total ErbB2 levels in $N f 2^{-1-}$ and $N f 2^{W T}$-expressing cells. $(B$, left $)$ Distribution of ErbB2 with CTxB-488 following 2 min of EGF stimulation in $N f 2^{-/-}$and $N f 2^{W T}$-expressing cells. Distribution (middle) and quantitation (right) of ErbB2 and TREGF 2 min after stimulation in $\mathrm{Nf}^{-/-}$cells treated with vehicle or $10 \mathrm{mM} \mathrm{M} \beta \mathrm{CD}$. (C, left) Distribution of pAkt in starved or TREGF-stimulated $N f 2^{-/-}$and $N f 2^{W T}$-expressing cells. (Right) $\mathrm{X}-\mathrm{Z}$ confocal images showing pAkt and F-actin in CDRs in EGFstimulated $\mathrm{Nf}^{-/-}$cells. (D) Distribution of TR-EGF and pAkt in $\mathrm{Nf}^{-/-}$cells infected with shScr- or shEzrin-expressing lentiviruses following $2 \mathrm{~min}$ of stimulation. Values show mean \pm SEM. $\left(^{* * *}\right) P<0.001$, Mann-Whitney $U$-test. Bars, $10 \mu \mathrm{m}$.

NF2-deficient cells are "addicted" to the advantage conferred by the recycling of ErbB and perhaps other mitogenic receptors. Our results suggest that altered trafficking of EGFR in NF2 ${ }^{-/-}$cells depends on increased membrane cholesterol (Fig. 6B). Altered cholesterol homeostasisparticularly the availability of hydroxymethylsterolshas been shown to impact EGFR/ErbB2 recycling (Sukhanova et al. 2013). We found that in both LDCs and SCs, Nf2 deficiency conferred increased sensitivity to ketoconazole, an inhibitor of sterol biosynthesis upstream of hydroxymethylsterol production (Fig. 7A). Importantly, this sensitivity was associated with a reduction in both Rab7 vesicle size and EGFR recycling (Fig. 7B,C). Thus, $\mathrm{Nf2}$-deficient cells may be particularly vulnerable to modulators of membrane cholesterol and receptor recycling.

Second, it is increasingly appreciated that macropinocytosis can be exploited for the delivery of therapeutics into tumor cells, in particular larger nanoparticles or biologics that are not membrane-permeable ( $\mathrm{Ha}$ et al. 2016). Another key example is extracellular vesicles (EVs), which can be drug-loaded and delivered into cells via macropinocytosis (Nakase et al. 2015; Costa Verdera et al. 2017). We asked whether $N f 2$ deficiency renders cells preferentially able to internalize fluorescently labeled EVs (PKH26-EVs). As shown in Figure 7D, Nf2 ${ }^{-/-}$ LDCs internalized PKH26-EVs with significantly

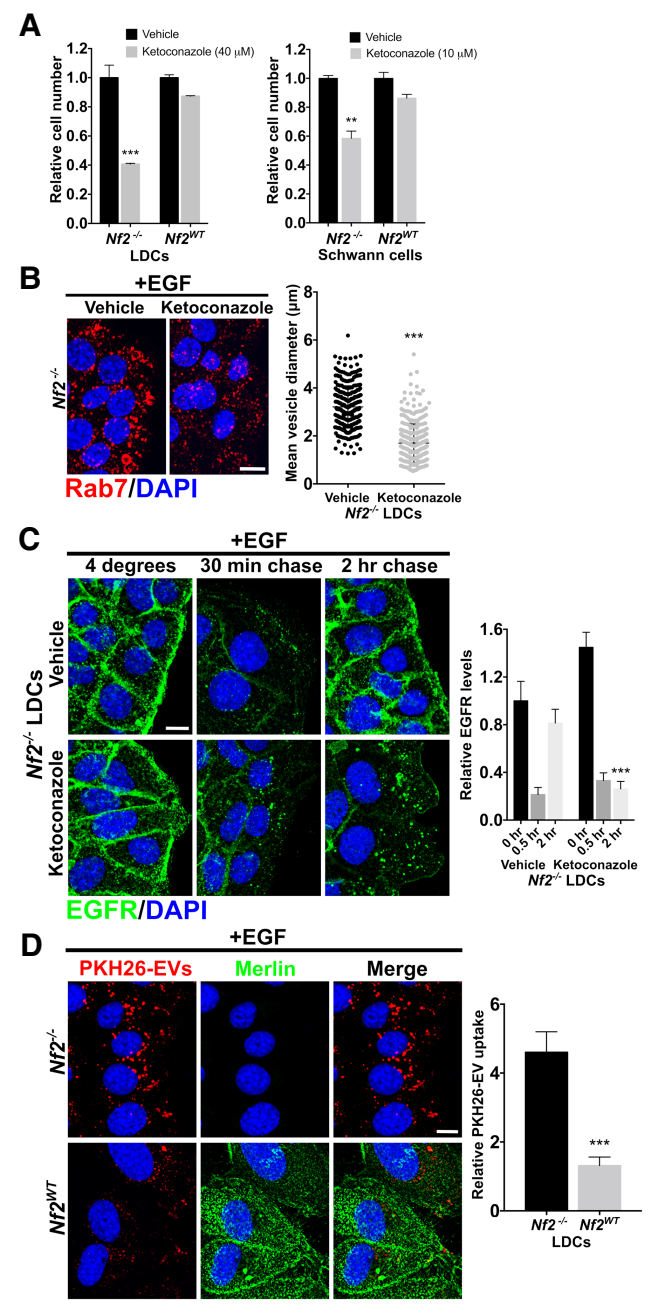

Figure 7. Therapeutic implications of macropinocytic priming in $N f 2^{-/-}$cells. (A) Sensitivity of $N f 2^{-/-}$versus $N f 2^{W T}$-expressing LDCs and $N f 2^{-/-}$versus control (Nf2 $\left.2^{\text {lox/lox }}\right)$ SCs to 72 h of treatment with ketoconazole relative to vehicle (DMSO). (B) Quantitation of $\mathrm{Rab}^{+}$vesicle size in EGF-stimulated $\mathrm{Nf2}^{-1-}$ and $N f 2^{W T}$-expressing cells treated with vehicle or ketoconazole. (C) Confocal images (left) and quantitation (right) of EGFR levels in $\mathrm{Nf2}^{-/-}$cells pretreated with cyclohexamide and stimulated with EGF for $30 \mathrm{~min}$ at $4^{\circ} \mathrm{C}$ and then transferred for $30 \mathrm{~min}$ or 2 $\mathrm{h}$ to $37^{\circ} \mathrm{C}$ following treatment with vehicle or ketaconazole. (D) Confocal images (left) and quantitation (right) of PKH26-labeled extracellular vesicles (EVs) internalized by EGF-stimulated $N f 2^{-l-}$ or $N f 2^{W T}$-expressing cells. Error bars represent mean \pm SEM. $\left(^{* *}\right) P<0.01 ;\left({ }^{* * *}\right) P<0.001$, Student's $t$-test for $A$ and Mann-Whitney $U$-test for $B-D$. Bars $10 \mu \mathrm{m}$. 
improved efficiency relative to $N f 2^{W T}$-expressing LDCs (Fig. 7D). Thus, Nf2-deficient cells may be particularly susceptible to targeting via therapeutics that use macropinocytic uptake.

\section{Discussion}

The membrane:cytoskeleton interface has a central but poorly understood role in regulating and responding to growth factor receptors. Our studies identified merlin/ ERMs as fundamental architects of this crucial cellular compartment and uncovered a novel role for them in regulating growth factor-induced macropinocytosis. Macropinocytosis is evolutionarily rooted in primitive means of nutrient acquisition that center on the interrelationship between nutrient sensing and morphological changes in the cell surface; its rediscovery as both a cellular behavior exploited by tumor cells and a conduit for drug delivery begs a deeper mechanistic understanding of the process in mammalian cells (Ha et al. 2016; Buckley and King 2017).

Our studies suggest that merlin deficiency "primes" cells for macropinocytosis by rendering the membrane:cytoskeleton interface particularly "excitable" to growth factor stimulation. They also implicate increased cortical ezrin in driving this excitability by concomitantly altering the configuration of cortical actomyosin and stabilizing cholesterol-rich membrane domains. Notably, ezrin was originally identified as a target of EGF-induced tyrosine phosphorylation that localizes to dorsal ruffles, supporting an active role in the membrane:cytoskeleton remodeling that enables macropinocytosis (Gould et al. 1986; Bretscher 1989; D'Angelo et al. 2007).

How do alterations in the membrane:cytoskeleton interface translate into significant changes in the "excitability" of cortical topography and signaling? The formation of a macropinocytic cup involves the establishment of a discrete domain of membrane:cytoskeleton dynamics and signaling that is sculpted by feedback (Swanson 2008). Like band 4.1, the prototype of the FERM protein family, merlin/ERMs likely simultaneously tether membrane proteins or lipids to the cortical cytoskeleton, impact cortical actin organization, and assemble protein complexes that locally regulate actin, membrane lipids, and/or receptors (McClatchey 2014). They are therefore poised to simultaneously impact both cytoskeletal and signaling responses to growth factor stimulation. A molecular understanding of how merlin and ezrin differentially configure the membrane:cytoskeleton interface awaits a dynamic high-resolution analysis of the cortical meshwork and associated membrane lipids, but it is notable that they interact quite differently with actin. The ERMs bind directly to actin filaments and are thought to align them parallel to the membrane (Thery and Bornens 2008; Fehon et al. 2010). Merlin lacks the ERM actin-binding domain but can interact with $\alpha$-catenin, an actin-binding protein that influences Arp2/3-driven actin branching (Drees et al. 2005; Gladden et al. 2010). Differences in cortical actin configuration and membrane:actin cross- linking could dramatically impact the formation and amplification of actin waves that underlie the dorsal and peripheral ruffles that initiate macropinocytosis via the differential recruitment of actin modifiers or modulation of membrane tension; those differences also impact receptor mobility and the diffusion of signals emanating from an activated receptor (Clayton and Cousin 2009; Gauthier et al. 2012; Kusumi et al. 2012; Bernitt et al. 2017).

The concomitant stabilization of cholesterol-rich domains within the plasma membrane of $N F 2^{-/-}$cells likely also influences the excitability of both cytoskeletal and signaling responses. The coordination between cortical actomyosin and cholesterol-rich domains is well established but poorly understood (Gowrishankar et al. 2012; Kusumi et al. 2012). Ezrin has been reported to influence this interface and could stabilize it by binding to and aggregating membrane $\mathrm{PI}(4,5) \mathrm{P}_{2}$, which clusters within cholesterol-rich membranes (Barret et al. 2000; Kwik et al. 2003; Prag et al. 2007; Martinelli et al. 2013; Santos et al. 2013; Senju et al. 2017). EGF-stimulated PI $(4,5) \mathrm{P}_{2}$ is essential for membrane ruffle formation and localizes to the vertically protruding rims of remodeling actin that surround PI3K-catalyzed $\mathrm{PI}(3,4,5) \mathrm{P}_{3}$ and form the walls of the macropinocytic cup (Araki et al. 2007). Cholesterol-rich domains may also amplify the signal from the activated EGFR itself, as has been shown for Fc receptors that initiate the related process of phagocytosis (Swanson 2008). A diffusion barrier must exist to prevent signal expansion and enable such a discrete structure to form, but the nature of such a barrier is unknown (Swanson 2008; Veltman et al. 2016). Local organization of the membrane:cytoskeleton interface is a clear candidate.

It is well known that internalized macropinosomes can undergo lysosomal processing, which is associated with the degradation of extracellular proteins as a source of amino acid nutrients, a feature exploited by Ras transformed pancreatic tumor cells (Commisso et al. 2013; Kamphorst et al. 2015; Davidson et al. 2017). We provide evidence that $\mathrm{NF}^{-/-}$cells do not exploit macropinocytosis for the acquisition and lysosomal processing of exogenous protein and instead preferentially recycle macropinosomes back to the cell surface, as can occur in certain settings (Buckley and King 2017). Internalized macropinosomes in $\mathrm{Nf2} 2^{-1-}$ cells are enlarged and accumulate Rab7 and the cholesterol-rich membrane marker CtxB-488. Enlarged Rab7-positive endocytic structures are associated with impaired lysosomal trafficking and decreased EGFR degradation (Jaber et al. 2016; Laviolette et al. 2017). Rab7 recruits clusters of dynein motors to cholesterol-rich membrane patches on internalized phagosomes to power their transport to the lysosome; however, cholesterol overloading, as in Neimann Pick disease, impedes this directed lysosomal transport and may favor the default kinesin-powered delivery back to the cell surface (Rocha et al. 2009; Rai et al. 2016). Our data are consistent with the notion that increased plasma membrane cholesterol in $\mathrm{NF}^{-/-}$cells favors macropinosome recycling rather than lysosomal transport.

We propose that the stabilization of cholesterol-rich membranes in $\mathrm{NF}^{-/-}$cells further impacts the signaling 
response to EGF by increasing the surface availability of ErbB2 and favoring the formation of EGFR:ErbB2 heterodimers that internalize via clathrin-independent endocytosis, transiently accumulate in a submembranous compartment, and recycle. Consistent with this model, increased ErbB2, which is known to prefer cholesterolrich membrane domains and can be stabilized at the surface via the ERM-binding adapter NHERF1, can promote recycling rather than degradation of EGFR and drive membrane-proximal PI3K activity (Hommelgaard et al. 2004; Offterdinger and Bastiaens 2008; Jeong et al. 2017). This feed-forward signaling, together with the appropriate actin configuration, could further optimize conditions for macropinocytosis and provide a distinct advantage to $\mathrm{NF2}^{-1-}$ cells.

Changes in the membrane:cytoskeleton interface, as occur in $\mathrm{NF}^{-/-}$cells, could trigger more stable cellular adaptation in differentiated tissues or disease states. Plasma membrane cholesterol and GM1 levels decrease in response to cellular crowding (Snijder et al. 2009). We showed previously that merlin/ERMs play an essential role in controlling EGFR trafficking and signaling in response to the mechanical forces imposed by high cell density (Chiasson-MacKenzie et al. 2015). It is tempting to speculate that, in addition to preferentially recycling, EGFR:ErbB2 heterodimers differentially signal to maintain an adapted state, perhaps by impacting cholesterol biosynthesis or transport (Nagy et al. 2002; Chung et al. 2010). Such broad changes in the plasma membrane:cytoskeleton interface conferred by merlin/ERMs likely impact other receptors; indeed, defects in other mitogenic and adhesion receptors have been reported in $\mathrm{NF}^{-1-}$ cells (Petrilli and Fernandez-Valle 2016). Our findings may help to explain the pleiotropic consequences of NF2 deficiency on multiple signaling pathways.

NF2 gene mutations occur in a range of human tumors (Petrilli and Fernandez-Valle 2016). Our work suggests new and broad ways to target NF2 mutant tumors. First, it may be possible to exploit their macropinocytic proficiency as a vulnerability. Unlike Ras transformed pancreatic tumor cells, NF2-deficient SCs and liver cells do not seem to depend on macropinocytic uptake and lysosomal degradation of extracellular protein as a source of nutrients (Commisso et al. 2013); instead, our data suggest that the macropinocytic recycling of receptors from cholesterolrich membranes is advantageous, raising the possibility that NF2 mutant tumors may be sensitive to drugs such as ketoconazole that interfere with specific aspects of cholesterol homeostasis or receptor recycling. These data also suggest that lysosomal protein degradation is not the only advantage that can be conferred by macropinocytosis. Second, mounting evidence suggests that macropinocytosis is an important route of therapeutic entry into cells (Ha et al. 2016). In proof-of-concept experiments we showed that $N 2^{-I-}$ cells preferentially take up labeled EVs, which have garnered great recent interest as biological nanocarriers for drug delivery. A better understanding of how the membrane:cytoskeleton interface is used for macropinocytic internalization and processing will have broad consequences for NF2 mutant and other tumor types.

\section{Materials and methods}

\section{Cell culture}

LDCs are HB-like cells derived from hyperplastic liver lesions in a 12 -wk-old Alb-Cre; Nf2 $2^{l o x / l o x}$ mouse as described (Chiasson-MacKenzie et al. 2015). Cells were cultured in DMEM with $10 \%$ fetal bovine serum (FBS). Adenovirus infection was used for Nf2 re-expression (Ad5-CMV-Nf2 $\left.{ }^{W T}\right)$. Primary murine SCs $\left(N f 2^{1 \text { lox } / \text { lox }}\right.$ or $\left.N f 1^{10 x / l o x}\right)$ were cultured on poly-L-lysine/laminin-coated plates in N2 medium (DMEM/F12-HAM, $1 \times$ N2 supplement [Thermo Fisher], $50 \mu \mathrm{g} / \mathrm{mL}$ gentamicin [Thermo Fisher], $2 \mu \mathrm{M}$ forskolin [Calbiochem], and $10 \mathrm{ng} / \mathrm{mL}$ Nrg [HRG- $\beta$-1 EGF domain] [R\&D Systems; provided by Marco Giovannini]) (Giovannini et al. 2000; Manent et al. 2003). Nf2 or Nf1 was deleted from lox/lox $\mathrm{SCs}$ via adenovirus infection with Cre-recombinase (Ad5-CMVCre). Human mesothelioma cell line HP-1 (provided by David Kwiatkowski, Brigham and Women's Hospital, Boston) was grown in 10\% FBS-DMEM. H2731 and NCI-H28 (provided by Cyril Benes, Massachusetts General Hospital Center for Molecular Therapeutics, Boston) were cultured in 10\% FBS-DMEM and $10 \%$ FBS-RPMI, respectively. $N f 2^{W T}$-expressing mesothelioma cells were prepared via adenoviral expression of $N f 2^{W T}$. 293A cells for adenovirus production (Agilent) and 293T cells for lentivirus production (American Type Culture Collection) were cultured in 10\% FBS-DMEM. All cell culture media were supplemented with $1 \%$ penicillin/streptomycin (Thermo Fisher).

\section{Growth factors and pharmacological inhibitors}

EGF (Peprotech) was used at $100 \mathrm{ng} / \mathrm{mL}$, and Nrg was used at 10 $\mathrm{ng} / \mathrm{mL}$. Drug pretreatment was as follows: $50 \mu \mathrm{M}$ EIPA (Sigma-Aldrich) for $60 \mathrm{~min}, 25 \mu \mathrm{M}$ HCQ (Sigma-Aldrich) for $48 \mathrm{~h}, 2.5 \mu \mathrm{M}$ FTY720 (Cayman) for $48 \mathrm{~h}, 1 \mu \mathrm{M}$ GDC0941 (Selleck) for $1 \mathrm{~h}, 40$ $\mu \mathrm{M}$ ketoconazole (Sigma-Aldrich) for $72 \mathrm{~h}$ (sensitivity) or $24 \mathrm{~h}$ (recycling), $1 \mu$ M BIBW2992 (Selleck) for $1 \mathrm{~h}, 10 \mathrm{mM} \mathrm{M \beta CD}$ (SigmaAldrich) for $30 \mathrm{~min}, 10 \mu \mathrm{M}$ latrunculin A (Cayman) for $15 \mathrm{~min}$, $5 \mu \mathrm{M}$ jasplakinolide for $15 \mathrm{~min}$, and $50 \mu \mathrm{g} / \mathrm{mL}$ cyclohexamide (Sigma-Aldrich) for $1 \mathrm{~h}$. These doses were maintained throughout the experiment.

\section{Plasmids and shRNA constructs}

The $N f 2^{W T}$ expression construct was generated by PCR amplification of the mouse Nf2-coding region and cloned into a pAdCMV vector as described (Chiasson-MacKenzie et al. 2015). The shRNA constructs targeting mouse ezrin $\left(5^{\prime}\right.$-ATTTCCT TGTTATAATCTCCG-3') in a pLKO-puro.1 vector were from GE Healthcare and were described in Hebert et al. (2012). The control (shScr; 5'-CAGTCGCGTTTGCGACTGG-3') in a pLKO-puro. 1 vector was provided by Marianne James (Massachusetts General Hospital, Boston) (James et al. 2008).

\section{Virus production and infection}

$N f 2^{W T}$-expressing and Cre-recombinase adenoviruses were generated using the AdEasy system (Agilent) as described in ChiassonMacKenzie et al. (2015). Cells were infected $24 \mathrm{~h}$ before the start of the experiment to induce $N f 2$ gene expression. An empty adenoviral vector was used as a control (EV). shRNA-expressing lentiviruses were generated by cotransfecting $293 \mathrm{~T}$ cells with pLKOpuro.1 vectors and the packaging vectors $\triangle \mathrm{VPR}$ and VSVG (Fugene). Viruses were harvested 24-48 h after transfection. shScr- or shEzrin-expressing lentiviruses were stably expressed in LDCs and selected in $4 \mu \mathrm{g} / \mathrm{mL}$ puromycin. 
Antibodies

The following primary antibodies were used: anti-ezrin mouse monoclonal antibody $(\mathrm{mAb} ; 1: 500$ for immunofluorescence; Neomarkers), anti-N-WASP rabbit polyclonal antibody (pAb; 1:100; Cell Signaling Technology), anti-Rab7 rabbit mAb (1:100; Cell Signaling Technology), anti-pAkt (S473) rabbit mAb (D9E, 1:100; Cell Signaling Technology), anti-pERK1/2 (T202/Y204) rabbit mAb (D13.14.4E, 1:100; Cell Signaling Technology), antiErbB2 rabbit pAb (1:100; Dako), and anti-Merlin rabbit pAb (1:500; Cell Signaling Technology). Alexa fluor 488-phalloidin or rhodamine-phalloidin (1:500; Thermo-Fisher) was used to label F-actin. Alexa fluor 488-CTxB (Thermo Fisher) was used to label membrane GM1. Species-specific secondary antibodies conjugated to Alexa fluor 488, 555, or 647 (Thermo Fisher) were used for immunofluorescence. DAPI was used to label nuclei.

\section{Immunofluorescence microscopy}

Cells were fixed in 4\% paraformaldehyde in PBS for 15 min at room temperature and then permeabilized in $0.2 \%$ Triton $\mathrm{X}$ 100 for $10 \mathrm{~min}$. Primary and secondary antibodies were diluted in PBS with $1 \%$ BSA and incubated for $1 \mathrm{~h}$ at room temperature. Alexa fluor-phalloidin was added with secondary antibodies. Coverslips were mounted with Prolong Gold anti-fade mountant (Thermo Fisher). Cells were imaged with an inverted laser-scanning confocal microscope (LSM710; Carl Zeiss) equipped with a $63 \times$ oil immersion objective (plan apochromat NA 1.4; Carl Zeiss). DAPI was excited with a 405-nm laser line of a diode laser. Alexa fluor 488, Alexa fluor 555, and rhodamine probes were excited with the 488-nm or 514-nm laser line of an argon laser. Texas red fluorescent probes were excited with the 561-nm laser line of a helium-neon laser. Alexa fluor 647 probes were excited with the $633-\mathrm{nm}$ laser line of a helium-neon laser. Images were acquired as single images or $z$-stacks in sequential mode using Zen Black software (2012 version; Carl Zeiss).

\section{Dextran/BSA uptake}

Cells grown on glass coverslips to $30 \%-40 \%$ confluency were serum-starved overnight and then stimulated with EGF or Nrg for 30 min. Dextran-488 (Oregon Green 488; 70,000, anionic, lysine-fixable) or BSA-488 (Alexa fluor 488 conjugate) (Thermo Fisher) was added at a concentration of $0.5 \mathrm{mg} / \mathrm{mL}$ with growth factors. Cells were rinsed three times with cold PBS and fixed with $4 \%$ paraformaldehyde. To measure constitutive macropinocytosis, dextran- 488 was added to complete growth medium for 30 min. For costaining with Rab7, cells were permeabilized with $0.2 \% \mathrm{TX}-100$ prior to staining.

\section{TR-EGF internalization and recycling}

LDCs were plated on 24-mm glass coverslips and grown to a confluency of $30 \%-40 \%$. TR-EGF internalization experiments were performed as described previously (Chiasson-MacKenzie et al. 2015). Prior to TR-EGF stimulation, cells were serum-starved overnight and incubated in DMEM/1\% BSA for $1 \mathrm{~h}$. Cells were stimulated with $2 \mu \mathrm{g} / \mathrm{mL}$ TR-EGF (Thermo Fisher) for 2, 10, or $30 \mathrm{~min}$ at $37^{\circ} \mathrm{C}$. Cells were rinsed three times with cold PBS. When noted, $10 \mu \mathrm{g} / \mathrm{mL}$ CTxB-488 was added with TR-EGF.

To measure EGFR recycling, cells were serum-starved overnight and treated with $50 \mu \mathrm{g} / \mathrm{mL}$ cyclohexamide for $1 \mathrm{~h}$. Cells were stimulated with $2 \mu \mathrm{g} / \mathrm{mL}$ TR-EGF for $30 \mathrm{~min}$ at $4^{\circ} \mathrm{C}$. Cells were washed twice with cold PBS and then shifted for $30 \mathrm{~min}$ or $2 \mathrm{~h}$ to $37^{\circ} \mathrm{C}$. Cyclohexamide was maintained in the medium throughout the experiment. Following fixation, cells were permeabilized and stained.

\section{Cell viability/drug treatment}

LDCs (5000 cells per well) or SCs (10,000 cells per well) were seeded in triplicate in 24-well plates in appropriate medium and allowed to adhere overnight. The drug was added $24 \mathrm{~h}$ after plating and incubated for 48 or $72 \mathrm{~h}$. Drugs were replenished every $24 \mathrm{~h}$. Cells were counted with a hemocytometer, and results were quantified as relative cell number compared with vehicle.

\section{Glutamine deprivation}

LDCs (5000 cells per well) or SCs (10,000 cells per well) were seeded in 24-well plates in triplicate. Twenty-four hours after plating, the medium was replaced with glutamine-free growth medium. Where noted, BSA was added to a final concentration of $2 \%$. The medium was replaced every $24 \mathrm{~h}$. Cells were grown for $6 \mathrm{~d}$, and final cell counts were determined using a hemocytometer and quantified as relative cell number compared with $\mathrm{Nf2}^{-/-}$cells in complete growth medium.

\section{EV production and uptake}

EVs were harvested as described previously (Reategui et al. 2018) from the conditioned medium of $\sim 1.0 \times 10^{8} \mathrm{Nf2}^{-/-}$LDCs. Fortyeight hours prior to harvesting, 10\% FBS/DMEM was replaced with DMEM with $100 \mathrm{ng} / \mathrm{mL}$ EGF for $48 \mathrm{~h}$. The medium was collected and centrifuged at $300 \mathrm{~g}$ for $10 \mathrm{~min}$ and at $2000 \mathrm{~g}$ for $10 \mathrm{~min}$. Supernatants were filtered (0.8 $\mu \mathrm{m}$; EMD Millipore) and ultracentrifuged at $100,000 \mathrm{~g}$ for $90 \mathrm{~min}$ at $4^{\circ} \mathrm{C}$ (Optima L-90K Ultracentrifuge, Beckman Coulter). Pelleted EVs were resuspended in $200 \mu \mathrm{L}$ of PBS. Purified EVs were labeled with PKH26 dye (Sigma-Aldrich) on a column and rinsed three times by centrifugation at $400 \mathrm{~g}$ for $10 \mathrm{~min}$. Labeled EVs were added to $\mathrm{Nf2} 2^{-/-}$or $N f 2^{W T}$-expressing LDCs at $\sim 10^{6}$ per $0.7 \mathrm{~cm}^{2}$ and incubated for $1 \mathrm{~h}$ at $37^{\circ} \mathrm{C}$. Cells were then fixed and stained.

\section{Image analysis and statistics}

ImageJ software (version 2.0, National Institutes of Health) was used for all image processing and analysis. The displayed images were produced from single confocal slices or maximum projections of $z$-stack images. Background was removed with rolling ball background subtraction. Lookup tables were applied to produce final images. CDRs were analyzed by counting the percentage of cells with CDRs from at least five random fields $(20 \times$ objective; $n>300$ cells). CDR height was measured by drawing a line from the surface of the cell to the tip of a CDR $(n=20)$. F-actin intensity was measured using the line scan function (Smutny et al. 2010). A line was drawn perpendicular to the free edge of a cell, and pixel intensity along the line was graphed using the plot profile function. The data were fit to a Gaussian curve using nonlinear regression analysis, and the mean amplitude of the curve was graphed $(n=20)$. Dextran, BSA, or EV uptake was measured using the "analyze particles" function to determine the ratio of total particle area to total cell area from at least five random fields. Vesicle size was analyzed by using a line to measure the diameter of vesicles labeled with dextran-488 or Rab7 from five random fields $(n>300)$. CTxB and ErbB2 levels were analyzed by measuring the integrated density of a cell using a thresholding mask within a region of interest $(n=20)$. For analysis of TR-EGF, $\mathrm{CTxB}$, or cholesterol enrichment at the free edge of cells, the sum of the pixel values (RawIntDen) was measured within a region of 
interest. TR-EGF internalization was measured by dividing the sum of the intensity of objects identified with a thresholding mask by the area of the cell $(n=20)$. Data from all analyses were imported into Prism 7 for plotting graphs and statistical analysis. The unpaired $t$-test or Mann-Whitney test was used to compare groups. All data are representative of three independent experiments.

\section{Acknowledgments}

We thank past and present members of the McClatchey laboratory for valuable discussions, and especially Marcello Curto for inspiring this line of investigation; Shannon Stott and Berent Aldikacti for their expertise in EV isolation; Marco Giovannini, Jeremie Vitte, Michel Kalamarides, David Kwiatkowski, and Cyril Benes for cell lines; and Kristin White for helpful comments. This work was supported by grants from the National Institutes of Health (R01 CA113733 to A.I.M., and T32 5T32CA00936135 to C.C.-M), US Department of Defense (W81XWH-16-1-0086 to A.I.M.), and Mesothelioma Applied Research Foundation (to A.I.M.) and fellowships from the Children's Tumor Foundation (to C.C.-M.) and EMBO (ALTF 552-2016 to T.K.). A.I.M. is the 2011 Patricia and Scott Eston Massachusetts General Hospital Research Scholar.

Author Contributions: The study was conceived and designed by C.C.-M., Z.S.M., and A.I.M. Experiments were carried out by C.C.-M., Z.S.M., C.-H.L., W.B.B., and T.K. Data were analyzed and interpreted by C.C.-M., T.K., and A.I.M. The project was supervised by A.I.M. Drafting of the manuscript and preparation of figures were completed by A.I.M. and C.C.-M. All authors read and commented on the manuscript.

\section{References}

Araki N, Egami Y, Watanabe Y, Hatae T. 2007. Phosphoinositide metabolism during membrane ruffling and macropinosome formation in EGF-stimulated A431 cells. Exp Cell Res 313: 1496-1507.

Barret C, Roy C, Montcourrier P, Mangeat P, Niggli V. 2000. Mutagenesis of the phosphatidylinositol 4,5-bisphosphate $\left(\mathrm{PIP}_{2}\right)$ binding site in the $\mathrm{NH}_{2}$-terminal domain of ezrin correlates with its altered cellular distribution. J Cell Biol 151: 1067-1080.

Bernitt E, Dobereiner HG, Gov NS, Yochelis A. 2017. Fronts and waves of actin polymerization in a bistability-based mechanism of circular dorsal ruffles. Nat Commun 8: 15863.

Bertelsen V, Stang E. 2014. The mysterious ways of ErbB2/HER2 trafficking. Membranes 4: 424-446.

Bloomfield G, Traynor D, Sander SP, Veltman DM, Pachebat JA, Kay RR. 2015. Neurofibromin controls macropinocytosis and phagocytosis in Dictyostelium. Elife 4: e04940.

Bretscher A. 1989. Rapid phosphorylation and reorganization of ezrin and spectrin accompany morphological changes induced in A-431 cells by epidermal growth factor. I Cell Biol 108: 921-930.

Buckley CM, King JS. 2017. Drinking problems: mechanisms of macropinosome formation and maturation. FEBS $J$ 284: 3778-3790.

Chiasson-MacKenzie C, McClatchey AI. 2018. Cell-cell contact and receptor tyrosine kinase signaling. Cold Spring Harb Perspect Biol 10: a029215.

Chiasson-MacKenzie C, Morris ZS, Baca Q, Morris B, Coker JK, Mirchev R, Jensen AE, Carey T, Stott SL, Golan DE, et al. 2015. NF2/Merlin mediates contact-dependent inhibition of
EGFR mobility and internalization via cortical actomyosin. $J$ Cell Biol 211: 391-405.

Chung I, Akita R, Vandlen R, Toomre D, Schlessinger J, Mellman I. 2010. Spatial control of EGF receptor activation by reversible dimerization on living cells. Nature 464: 783-787.

Cichowski K, Jacks T. 2001. NF1 tumor suppressor gene function: narrowing the GAP. Cell 104: 593-604.

Clayton EL, Cousin MA. 2009. The molecular physiology of activity-dependent bulk endocytosis of synaptic vesicles. J Neurochem 111: 901-914.

Commisso C, Davidson SM, Soydaner-Azeloglu RG, Parker SJ, Kamphorst JJ, Hackett S, Grabocka E, Nofal M, Drebin JA, Thompson CB, et al. 2013. Macropinocytosis of protein is an amino acid supply route in Ras-transformed cells. Nature 497: 633-637.

Costa Verdera H, Gitz-Francois JJ, Schiffelers RM, Vader P. 2017. Cellular uptake of extracellular vesicles is mediated by clathrin-independent endocytosis and macropinocytosis. J Control Release 266: 100-108.

Curto M, Cole BK, Lallemand D, Liu CH, McClatchey AI. 2007. Contact-dependent inhibition of EGFR signaling by Nf2/Merlin. J Cell Biol 177: 893-903.

D'Angelo R, Aresta S, Blangy A, Del Maestro L, Louvard D, Arpin M. 2007. Interaction of ezrin with the novel guanine nucleotide exchange factor PLEKHG6 promotes RhoG-dependent apical cytoskeleton rearrangements in epithelial cells. Mol Biol Cell 18: 4780-4793.

Davidson SM, Jonas O, Keibler MA, Hou HW, Luengo A, Mayers JR, Wyckoff J, Del Rosario AM, Whitman M, Chin CR, et al. 2017. Direct evidence for cancer-cell-autonomous extracellular protein catabolism in pancreatic tumors. Nat Med 23: 235-241.

Devreotes PN, Bhattacharya S, Edwards M, Iglesias PA, Lampert T, Miao Y. 2017. Excitable signal transduction networks in directed cell migration. Annu Rev Cell Dev Biol 33: 103-125.

Drees F, Pokutta S, Yamada S, Nelson WJ, Weis WI. 2005. a-Catenin is a molecular switch that binds E-cadherin- $\beta$-catenin and regulates actin-filament assembly. Cell 123: 903-915.

Fehon RG, McClatchey AI, Bretscher A. 2010. Organizing the cell cortex: the role of ERM proteins. Nat Rev Mol Cell Biol 11: 276-287.

Francavilla C, Papetti M, Rigbolt KT, Pedersen AK, Sigurdsson JO, Cazzamali G, Karemore G, Blagoev B, Olsen JV. 2016. Multilayered proteomics reveals molecular switches dictating ligand-dependent EGFR trafficking. Nat Struct Mol Biol 23: 608-618.

Gauthier NC, Masters TA, Sheetz MP. 2012. Mechanical feedback between membrane tension and dynamics. Trends Cell Biol 22: 527-535.

Giovannini M, Robanus-Maandag E, van der Valk M, NiwaKawakita M, Abramowski V, Goutebroze L, Woodruff JM, Berns A, Thomas G. 2000. Conditional biallelic Nf2 mutation in the mouse promotes manifestations of human neurofibromatosis type 2. Genes Dev 14: 1617-1630.

Gladden AB, Hebert AM, Schneeberger EE, McClatchey AI. 2010. The NF2 tumor suppressor, Merlin, regulates epidermal development through the establishment of a junctional polarity complex. Dev Cell 19: 727-739.

Gould KL, Cooper JA, Bretscher A, Hunter T. 1986. The proteintyrosine kinase substrate, $\mathrm{p} 81$, is homologous to a chicken microvillar core protein. J Cell Biol 102: 660-669.

Gowrishankar K, Ghosh S, Saha S, C R, Mayor S, Rao M. 2012. Active remodeling of cortical actin regulates spatiotemporal organization of cell surface molecules. Cell 149: 1353-1367. 
Grimmer S, van Deurs B, Sandvig K. 2002. Membrane ruffling and macropinocytosis in A431 cells require cholesterol. I Cell Sci 115: 2953-2962.

Ha KD, Bidlingmaier SM, Liu B. 2016. Macropinocytosis exploitation by cancers and cancer therapeutics. Front Physiol 7: 381 .

Haslekas C, Breen K, Pedersen KW, Johannessen LE, Stang E, Madshus IH. 2005. The inhibitory effect of ErbB2 on epidermal growth factor-induced formation of clathrin-coated pits correlates with retention of epidermal growth factor receptor-ErbB2 oligomeric complexes at the plasma membrane. Mol Biol Cell 16: 5832-5842.

Hebert AM, DuBoff B, Casaletto JB, Gladden AB, McClatchey AI. 2012. Merlin/ERM proteins establish cortical asymmetry and centrosome position. Genes Dev 26: 2709-2723.

Hendriks BS, Opresko LK, Wiley HS, Lauffenburger D. 2003. Coregulation of epidermal growth factor receptor/human epidermal growth factor receptor 2 (HER2) levels and locations: quantitative analysis of HER2 overexpression effects. Cancer Res 63: 1130-1137.

Hommelgaard AM, Lerdrup M, van Deurs B. 2004. Association with membrane protrusions makes ErbB2 an internalizationresistant receptor. Mol Biol Cell 15: 1557-1567.

Huynh KK, Gershenzon E, Grinstein S. 2008. Cholesterol accumulation by macrophages impairs phagosome maturation. I Biol Chem 283: 35745-35755.

Jaber N, Mohd-Naim N, Wang Z, DeLeon JL, Kim S, Zhong H, Sheshadri N, Dou Z, Edinger AL, Du G, et al. 2016. Vps34 regulates Rab7 and late endocytic trafficking through recruitment of the GTPase-activating protein Armus. I Cell Sci 129: 4424-4435.

James MF, Lelke JM, Maccollin M, Plotkin SR, Stemmer-Rachamimov AO, Ramesh V, Gusella JF. 2008. Modeling NF2 with human arachnoidal and meningioma cell culture systems: NF2 silencing reflects the benign character of tumor growth. Neurobiol Dis 29: 278-292.

Jaqaman K, Grinstein S. 2012. Regulation from within: the cytoskeleton in transmembrane signaling. Trends Cell Biol 22: 515-526.

Jeong J, VanHouten JN, Kim W, Dann P, Sullivan C, Choi J, Sneddon WB, Friedman PA, Wysolmerski JJ. 2017. The scaffolding protein NHERF1 regulates the stability and activity of the tyrosine kinase HER2. J Biol Chem 292: 6555-6568.

Kamphorst JJ, Nofal M, Commisso C, Hackett SR, Lu W, Grabocka E, Vander Heiden MG, Miller G, Drebin JA, Bar-Sagi D, et al. 2015. Human pancreatic cancer tumors are nutrient poor and tumor cells actively scavenge extracellular protein. Cancer Res 75: 544-553.

Kerr MC, Teasdale RD. 2009. Defining macropinocytosis. Traffic 10: 364-371.

Kim SM, Roy SG, Chen B, Nguyen TM, McMonigle RJ, McCracken AN, Zhang Y, Kofuji S, Hou J, Selwan E, et al. 2016. Targeting cancer metabolism by simultaneously disrupting parallel nutrient access pathways. J Clin Invest 126: 4088-4102.

Koivusalo M, Welch C, Hayashi H, Scott CC, Kim M, Alexander T, Touret N, Hahn KM, Grinstein S. 2010. Amiloride inhibits macropinocytosis by lowering submembranous $\mathrm{pH}$ and preventing Rac1 and Cdc42 signaling. J Cell Biol 188: 547-563.

Kusumi A, Fujiwara TK, Morone N, Yoshida KJ, Chadda R, Xie M, Kasai RS, Suzuki KG. 2012. Membrane mechanisms for signal transduction: the coupling of the meso-scale raft domains to membrane-skeleton-induced compartments and dynamic protein complexes. Semin Cell Dev Biol 23: 126-144.

Kwik J, Boyle S, Fooksman D, Margolis L, Sheetz MP, Edidin M. 2003. Membrane cholesterol, lateral mobility, and the phos- phatidylinositol 4,5-bisphosphate-dependent organization of cell actin. Proc Natl Acad Sci 100: 13964-13969.

Laviolette LA, Mermoud J, Calvo IA, Olson N, Boukhali M, Steinlein OK, Roider E, Sattler EC, Huang D, Teh BT, et al. 2017. Negative regulation of EGFR signalling by the human folliculin tumour suppressor protein. Nat Commun 8: 15866.

Lemmon MA, Schlessinger J, Ferguson KM. 2014. The EGFR family: not so prototypical receptor tyrosine kinases. Cold Spring Harb Perspect Biol 6: a020768.

Li Y, Macdonald-Obermann J, Westfall C, Piwnica-Worms D, Pike LJ. 2012. Quantitation of the effect of ErbB2 on epidermal growth factor receptor binding and dimerization. J Biol Chem 287: 31116-31125.

Lin AL, Gutmann DH. 2013. Advances in the treatment of neurofibromatosis-associated tumours. Nat Rev Clin Oncol 10: 616-624.

Maekawa M, Terasaka S, Mochizuki Y, Kawai K, Ikeda Y, Araki N, Skolnik EY, Taguchi T, Arai H. 2014. Sequential breakdown of 3-phosphorylated phosphoinositides is essential for the completion of macropinocytosis. Proc Natl Acad Sci 111: E978-E987.

Manent J, Oguievetskaia K, Bayer J, Ratner N, Giovannini M. 2003. Magnetic cell sorting for enriching Schwann cells from adult mouse peripheral nerves. I Neurosci Methods 123: $167-173$.

Martinelli S, Chen EJ, Clarke F, Lyck R, Affentranger S, Burkhardt JK, Niggli V. 2013. Ezrin/Radixin/Moesin proteins and flotillins cooperate to promote uropod formation in T cells. Front Immunol 4: 84 .

Maxfield FR, Wustner D. 2012. Analysis of cholesterol trafficking with fluorescent probes. Methods Cell Biol 108: 367-393.

McClatchey AI. 2014. ERM proteins at a glance. J Cell Sci 127: 3199-3204.

Mercer J, Helenius A. 2009. Virus entry by macropinocytosis. Nat Cell Biol 11: 510-520.

Nagy P, Vereb G, Sebestyen Z, Horvath G, Lockett SJ, Damjanovich S, Park JW, Jovin TM, Szollosi J. 2002. Lipid rafts and the local density of ErbB proteins influence the biological role of homo- and heteroassociations of ErbB2. I Cell Sci 115: 4251-4262.

Nakase I, Kobayashi NB, Takatani-Nakase T, Yoshida T. 2015. Active macropinocytosis induction by stimulation of epidermal growth factor receptor and oncogenic Ras expression potentiates cellular uptake efficacy of exosomes. Sci Rep 5: 10300.

Offterdinger M, Bastiaens PI. 2008. Prolonged EGFR signaling by ERBB2-mediated sequestration at the plasma membrane. Traffic 9: 147-155.

Orth JD, Krueger EW, Weller SG, McNiven MA. 2006. A novel endocytic mechanism of epidermal growth factor receptor sequestration and internalization. Cancer Res 66: 3603-3610.

Petrilli AM, Fernandez-Valle C. 2016. Role of Merlin/NF2 inactivation in tumor biology. Oncogene 35: 537-548.

Prag S, Parsons M, Keppler MD, Ameer-Beg SM, Barber P, Hunt J, Beavil AJ, Calvert R, Arpin M, Vojnovic B, et al. 2007. Activated ezrin promotes cell migration through recruitment of the GEF Dbl to lipid rafts and preferential downstream activation of Cdc42. Mol Biol Cell 18: 2935-2948.

Rai A, Pathak D, Thakur S, Singh S, Dubey AK, Mallik R. 2016. Dynein clusters into lipid microdomains on phagosomes to drive rapid transport toward lysosomes. Cell 164: 722-734.

Reategui E, van der Vos KE, Lai CP, Zeinali M, Atai NA, Aldikacti B, Floyd FP Jr., Khankhel AH, Thapar V, Hochberg FH, et al. 2018. Engineered nanointerfaces for microfluidic isolation 
and molecular profiling of tumor-specific extracellular vesicles. Nat Commun 9: 175.

Rocha N, Kuijl C, van der Kant R, Janssen L, Houben D, Janssen H, Zwart W, Neefjes J. 2009. Cholesterol sensor ORP1L contacts the ER protein VAP to control Rab7-RILP-p150 Glued and late endosome positioning. J Cell Biol 185: 1209-1225.

Rotsch C, Radmacher M. 2000. Drug-induced changes of cytoskeletal structure and mechanics in fibroblasts: an atomic force microscopy study. Biophys J 78: 520-535.

Salzer JL. 2015. Schwann cell myelination. Cold Spring Harb Perspect Biol 7: a020529.

Santos AJ, Meinecke M, Fessler MB, Holden DW, Boucrot E. 2013. Preferential invasion of mitotic cells by Salmonella reveals that cell surface cholesterol is maximal during metaphase. J Cell Sci 126: 2990-2996.

Schmees C, Villasenor R, Zheng W, Ma H, Zerial M, Heldin CH, Hellberg C. 2012. Macropinocytosis of the PDGF $\beta$-receptor promotes fibroblast transformation by H-RasG12V. Mol Biol Cell 23: 2571-2582.

Senju Y, Kalimeri M, Koskela EV, Somerharju P, Zhao H, Vattulainen I, Lappalainen P. 2017. Mechanistic principles underlying regulation of the actin cytoskeleton by phosphoinositides. Proc Natl Acad Sci 114: E8977-E8986.

Smutny M, Cox HL, Leerberg JM, Kovacs EM, Conti MA, Ferguson C, Hamilton NA, Parton RG, Adelstein RS, Yap AS. 2010. Myosin II isoforms identify distinct functional modules that support integrity of the epithelial zonula adherens. Nat Cell Biol 12: 696-702.

Snijder B, Sacher R, Ramo P, Damm EM, Liberali P, Pelkmans L. 2009. Population context determines cell-to-cell variability in endocytosis and virus infection. Nature 461: 520-523.

Sobo K, Le Blanc I, Luyet PP, Fivaz M, Ferguson C, Parton RG, Gruenberg J, van der Goot FG. 2007. Late endosomal cholesterol accumulation leads to impaired intra-endosomal trafficking. PLoS One 2: e851.

Sukhanova A, Gorin A, Serebriiskii IG, Gabitova L, Zheng H, Restifo D, Egleston BL, Cunningham D, Bagnyukova T, Liu H, et al. 2013. Targeting C4-demethylating genes in the cholesterol pathway sensitizes cancer cells to EGF receptor inhibitors via increased EGF receptor degradation. Cancer Discov 3: 96-111.

Swanson JA. 2008. Shaping cups into phagosomes and macropinosomes. Nat Rev Mol Cell Biol 9: 639-649.

Thery M, Bornens M. 2008. Get round and stiff for mitosis. HFSP J 2: 65-71.

Tomas A, Futter CE, Eden ER. 2014. EGF receptor trafficking: consequences for signaling and cancer. Trends Cell Biol 24: 26-34.

Veltman DM, Lemieux MG, Knecht DA, Insall RH. 2014. PIP $3^{-}$ dependent macropinocytosis is incompatible with chemotaxis. J Cell Biol 204: 497-505.

Veltman DM, Williams TD, Bloomfield G, Chen BC, Betzig E, Insall RH, Kay RR. 2016. A plasma membrane template for macropinocytic cups. Elife 5: e20085. 


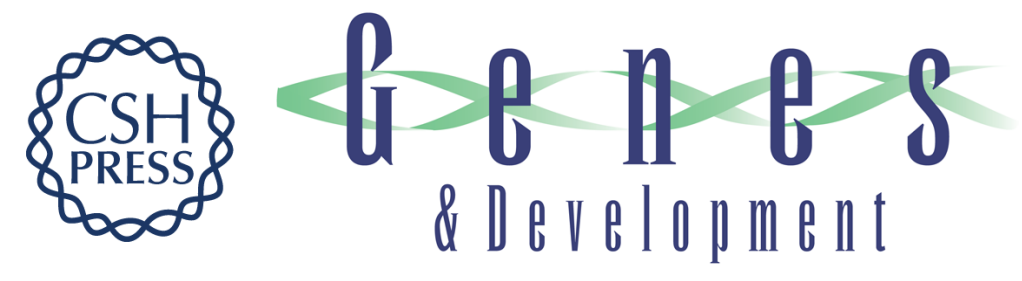

\section{Merlin/ERM proteins regulate growth factor-induced macropinocytosis and receptor recycling by organizing the plasma membrane:cytoskeleton interface}

Christine Chiasson-MacKenzie, Zachary S. Morris, Ching-Hui Liu, et al.

Genes Dev. 2018, 32: originally published online August 24, 2018

Access the most recent version at doi:10.1101/gad.317354.118

Supplemental Material

References

Creative

Commons

License

Email Alerting

Service
http://genesdev.cshlp.org/content/suppl/2018/08/24/gad.317354.118.DC1

This article cites 76 articles, 33 of which can be accessed free at: http://genesdev.cshlp.org/content/32/17-18/1201.full.html\#ref-list-1

This article is distributed exclusively by Cold Spring Harbor Laboratory Press for the first six months after the full-issue publication date (see http://genesdev.cshlp.org/site/misc/terms.xhtml). After six months, it is available under a Creative Commons License (Attribution-NonCommercial 4.0 International), as described at http://creativecommons.org/licenses/by-nc/4.0/.

Receive free email alerts when new articles cite this article - sign up in the box at the top right corner of the article or click here.

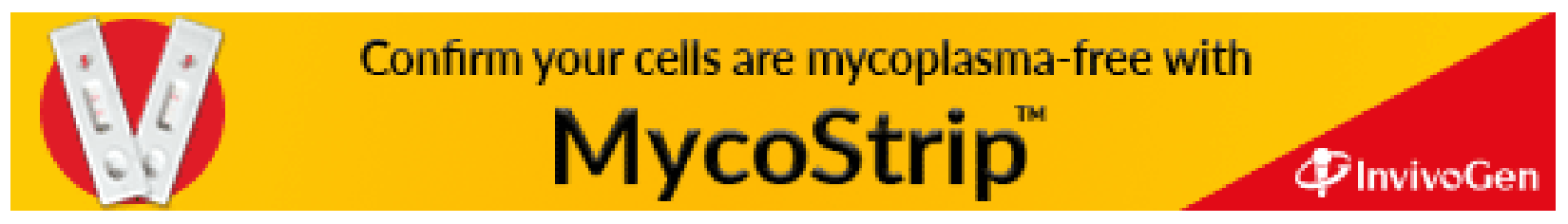

